\title{
Metal-Organic Framework MIL-101: Synthesis and Photocatalytic Degradation of Remazol Black B Dye
}

\author{
Pham Dinh Du ${ }^{10},{ }^{1}$ Huynh Thi Minh Thanh, ${ }^{2,3}$ Thuy Chau To, ${ }^{1}$ Ho Sy Thang, \\ Mai Xuan Tinh, ${ }^{3}$ Tran Ngoc Tuyen, ${ }^{3}$ Tran Thai Hoa $\mathbb{D}^{3},{ }^{3}$ and Dinh Quang Khieu ${ }^{3}{ }^{3}$ \\ ${ }^{1}$ Faculty of Natural Science, Thu Dau Mot University, 820000, Vietnam \\ ${ }^{2}$ Department of Chemistry, Quy Nhon University, 59000, Vietnam \\ ${ }^{3}$ University of Sciences, Hue University, 530000, Vietnam \\ ${ }^{4}$ Dong Thap University, 870000, Vietnam \\ Correspondence should be addressed to Dinh Quang Khieu; dqkhieu@hueuni.edu.vn
}

Received 20 January 2019; Revised 2 April 2019; Accepted 28 April 2019; Published 14 May 2019

Guest Editor: Soubantika Palchoudhury

Copyright ( $) 2019$ Pham Dinh Du et al. This is an open access article distributed under the Creative Commons Attribution License, which permits unrestricted use, distribution, and reproduction in any medium, provided the original work is properly cited.

In the present paper, the synthesis of metal-organic framework MIL-101 and its application in the photocatalytic degradation of Remazol Black B (RBB) dye have been demonstrated. The obtained samples were characterized by X-ray diffraction (XRD), transmission electron microscope (TEM), X-ray photoelectron spectroscopy (XPS), and nitrogen adsorption/desorption isotherms at $77 \mathrm{~K}$. It was found that MIL-101 synthesized under optimal conditions exhibited high crystallinity and specific surface area $\left(3360 \mathrm{~m}^{2} \cdot \mathrm{g}^{-1}\right)$. The obtained MIL-101 possessed high stability in water for 14 days and several solvents (benzene, ethanol, and water at boiling temperature). Its catalytic activities were evaluated by measuring the degradation of RBB in an aqueous solution under UV radiation. The findings show that MIL-101 was a heterogeneous photocatalyst in the degradation reaction of $\mathrm{RBB}$. The mechanism of photocatalysis was considered to be achieved by the electron transfer from photoexcited organic ligands to metallic clusters in MIL-101. The kinetics of photocatalytic degradation reaction were analyzed by using the initial rate method and Langmuir-Hinshelwood model. The MIL-101 photocatalyst exhibited excellent catalytic recyclability and stability and can be a potential catalyst for the treatment of organic pollutants in aqueous solutions.

\section{Introduction}

Textile and paint industries and dyestuff manufacturing release a considerable amount of wastewater with dyes. This has raised serious environmental concerns all over the world; thus, their removal is of interest to many scientists [1]. Dyes are difficult to treat along with municipal waste treatment operations due to their complicated chemical structures. Remazol Black B (RBB) is a popular diazo reactive dye and used widely in textile industries [2]. Various processes for eliminating RBB from aqueous solutions including adsorption, electrochemistry, and biosorption have been reported. Thi Thanh et al. [3] reported the efficient removal of RBB using iron-containing zeolite imidazole framework-8 (Fe-ZIF-8). Fe-ZIF-8 possessed high stability. After three cycles, the degradation yield was reduced slightly- $-95 \%$ compared to the initial catalyst. Soloman et al. [2] reported the degradation of hydrolyzed Remazol Black using the electrochemical approach. Brazilian pine-fruit shells (Araucaria angustifolia) in natural form are efficient adsorbents for the removal of RBB dye from aqueous effluents [4]. Biosorption of an azo dye by growing fungi (Aspergillus flavus) was reported in which the removal of chemical oxygen demand (COD) was found to be $90 \%$ at $100 \mathrm{mg} \cdot \mathrm{L}^{-1}$ initial concentration of dye [5]. The introduction of iron to ZIF-8 significantly enhanced the photocatalytic degradation of RBB Fe-ZIF- 8 under visible light [6].

Metal-organic frameworks (MOFs) are porous materials formed via strong metal-ligand bonds between metal cations and organic linkers $[7,8]$. MOFs have many applications in gas storage [9-15], separation [16, 17], and heterogeneous catalysis [18-21]. MIL-101 is a member of the 
large family of MOFs with the largest Langmuir surface area $\left(4500 \mathrm{~m}^{2} \cdot \mathrm{g}^{-1}\right)$, pore size $(29-34 \AA)$, and cell volume (702.000 $)$. It was first reported by Férey et al. in 2005 [22], who synthesized it from HF- $\mathrm{Cr}\left(\mathrm{NO}_{3}\right)_{3}$-1,4-dicarboxylic acid- $\left(\mathrm{H}_{2} \mathrm{BDC}-\mathrm{H}_{2} \mathrm{O}\right.$. Since the discovery of large-pore MIL101, several groups have tried to synthesize MIL-101 for gas adsorption. However, it is hard to obtain crystalline MIL101 with a high BET surface of more than $3200 \mathrm{~m}^{2} \cdot \mathrm{g}^{-1}$ [18] because of the presence of $\mathrm{H}_{2} \mathrm{BDC}$ residue or inorganic impurities in the pores as well as outside the pores. In the synthesis of MIL-101, it is complicated to remove most of the nonreacted $\mathrm{H}_{2} \mathrm{BDC}$ present both outside and within the pores of MIL-101. Yang et al. [13] used various alkalis, such as potassium hydroxide $(\mathrm{KOH})$, tetramethylammonium hydroxide (TMAOH), triethylamine $\left(\left(\mathrm{C}_{2} \mathrm{H}_{5}\right)_{3} \mathrm{~N}\right)$, dimethylamine $\left(\mathrm{C}_{2} \mathrm{H}_{7} \mathrm{~N}\right)$, methylamine $\left(\mathrm{CH}_{5} \mathrm{~N}\right)$, and ammonia $\left(\mathrm{NH}_{3}\right)$, to avoid recrystallization of $\mathrm{H}_{2} \mathrm{BDC}$. The TMAOH$\mathrm{Cr}\left(\mathrm{NO}_{3}\right)_{3}-\mathrm{H}_{2} \mathrm{BDC}-\mathrm{H}_{2} \mathrm{O}$ system was found to be suitable for obtaining MIL-101 with high surface properties. Hong et al. [18] reported a separation process in which huge amounts of $\mathrm{H}_{2} \mathrm{BDC}$ were separated with a fritted glass filter, and then excess dissolution was done with a hot solvent (ethanol or $\mathrm{N}, \mathrm{N}$-dimethyl-formamide $\left(\mathrm{NH}_{4} \mathrm{~F}\right)$ ).

The heterogeneous photocatalysis is one of the highly effective methods used for the treatment of a wide variety of organic pollutants owing to its ability to degrade the pollutants completely. Photocatalytic degradation is usually conducted for dissolved compounds in water, at mild temperature and pressure conditions, using UV radiation and photocatalytic semiconductors without any requirement of expensive oxidants. The use of metal-organic frameworks (MOFs) as photocatalysts is a new field of application for this material. Recently, some MOF materials such as MOF5 [23-25], MIL-125 [26], and MIL-53(M) $(\mathrm{M}=\mathrm{Fe}, \mathrm{Al}$, and Cr) [27] have been applied successfully in the decolorization of various dyes in aqueous solutions. Owing to its excellent porosities (high specific surface area, large pore volume, and uniform pores), MIL-101 is a good candidate in catalysis [28] and has been found to be a great candidate for many other applications $[16,17,29-32]$. Several papers have reported visible-light photocatalytic activity of modified MIL-101, e.g., $\mathrm{N}-\mathrm{K}_{2} \mathrm{Ti}_{4} \mathrm{O}_{9} / \mathrm{MIL}-101$ composite [33] and $\mathrm{Bi}_{25} \mathrm{FeO}_{40} / \mathrm{MIL}-101 / \mathrm{PTH}$ [34]. To the best of our knowledge, no attention has ever been paid to the study of the photocatalytic properties of pure MIL-101 to date.

In the present paper, we focused on an $\mathrm{Cr}\left(\mathrm{NO}_{3}\right)_{3}$ $\mathrm{H}_{2} \mathrm{BDC}-\mathrm{H}_{2} \mathrm{O}$ system and analyzed the effect of different conditions on the synthesis of MIL-101 and monitored the hydrothermal stability of MIL-101 in various solvents and conditions. Photocatalytic degradation of RBB was also investigated.

\section{Experimental}

2.1. Materials. Chromium(III) nitrate nonahydrate $\left(\mathrm{Cr}\left(\mathrm{NO}_{3}\right)_{3} \cdot 9 \mathrm{H}_{2} \mathrm{O} ;\right.$ 99\%), benzene-1,4-dicarboxylic acid $\left(\mathrm{C}_{6} \mathrm{H}_{4}(\mathrm{COOH})_{2} ;>98 \%\right.$ ) (denoted as $\mathrm{H}_{2} \mathrm{BDC}$ ), and hydrogen fluoride (HF; 40\%) were purchased from Merck, Germany. Remazol Black B $\left(\mathrm{C}_{26} \mathrm{H}_{21} \mathrm{~N}_{5} \mathrm{Na}_{4} \mathrm{O}_{19} \mathrm{~S}_{6}\right.$, molecular weight $=$
991.82) (denoted as RBB) was procured from the Thuy Duong Textile Company (Hue city, Vietnam). The structure of RBB is shown in Scheme 1.

Ferrous ammonium sulfate $\left(\mathrm{Fe}\left(\mathrm{NH}_{4}\right)_{2}\left(\mathrm{SO}_{4}\right)_{2} 6 \mathrm{H}_{2} \mathrm{O}\right.$; $>98 \%)$, potassium dichromate $\left(\mathrm{K}_{2} \mathrm{Cr}_{2} \mathrm{O}_{7} ;>99 \%\right)$, ferrous sulfate heptahydrate $\left(\mathrm{FeSO}_{4} \cdot 7 \mathrm{H}_{2} \mathrm{O} ;>99 \%\right)$, silver sulfate ( $\left.\mathrm{Ag}_{2} \mathrm{SO}_{4} ;>99 \%\right)$, conc. $\mathrm{H}_{2} \mathrm{SO}_{4}(98 \%)$, and mercuric sulfate $\left(\mathrm{HgSO}_{4} ;>98 \%\right)$ were supplied from Merck, Germany, and used to measure the COD of samples.

2.2. MIL-101 Synthesis. MIL-101 was synthesized according to an earlier report with some modifications [22]. The mixture of reactants including $\mathrm{H}_{2} \mathrm{BDC}, \mathrm{Cr}\left(\mathrm{NO}_{3}\right)_{3}, \mathrm{HF}$, and $\mathrm{H}_{2} \mathrm{O}$ was heated in a Teflon-lined stainless steel autoclave at $200^{\circ} \mathrm{C}$ for $8 \mathrm{~h}$. The resulting green solid material was filtered using a $0.2 \mu \mathrm{m}$ membrane and then extracted in ethanol with Soxhlet equipment for $12 \mathrm{~h}$ to remove residual amount of $\mathrm{H}_{2} \mathrm{BDC}$ still present in the product. The effects of the molar ratio of chromium nitrate and water to $\mathrm{H}_{2} \mathrm{BDC}$ on the formation of MIL-101 were also monitored. With a fixed water volume of $100 \mathrm{~mL}$, the composition of the synthesized gel was calculated at the following molar ratio:

(i) For the study on the effect of the molar ratio of $\mathrm{Cr} / \mathrm{H}_{2} \mathrm{BDC}$, the molar composition of a reactant mixture of $\mathrm{H}_{2} \mathrm{BDC}: \mathrm{Cr}\left(\mathrm{NO}_{3}\right)_{3} \cdot 9 \mathrm{H}_{2} \mathrm{O}: \mathrm{HF}: \mathrm{H}_{2} \mathrm{O}=$ $1.00: x: 0.25: 265$, with $x=0.5,0.75,1.00,1.25$, 1.50 , and 1.75 . The samples were denoted as M-0.5, $\mathrm{M}-0.75, \mathrm{M}-1.00, \mathrm{M}-1.25, \mathrm{M}-1.50$, and M-1.75

(ii) For the study on the effect of the ratio of $\mathrm{H}_{2} \mathrm{O} / \mathrm{H}_{2} \mathrm{BDC}$, the molar composition of a reactant mixture of $\mathrm{H}_{2} \mathrm{BDC}: \mathrm{Cr}\left(\mathrm{NO}_{3}\right)_{3} \cdot 9 \mathrm{H}_{2} \mathrm{O}: \mathrm{HF}: \mathrm{H}_{2} \mathrm{O}=$ $1.00: 1.25: 0.25: y$, with $y=200,265,350,400,500$, and 700. The samples were denoted as M-200, M265, M-350, M-400, M-500, and M-700

2.3. Photocatalytic Performance. The photocatalytic degradation of RBB was measured at ambient conditions using a set of home-made equipment. The source of UV light was UV-B313 $30 \mathrm{~W}(\lambda=310 \mathrm{~nm})$.

The photocatalytic experiments were performed in a $1000 \mathrm{~mL}$ beaker containing $500 \mathrm{~mL}$ of aqueous suspensions of $10-50 \mathrm{ppm}$ RBB and a $0.25 \mathrm{mg}$ catalyst. The beaker was kept at $25^{\circ} \mathrm{C}$ with a thermostat. The UV lamp was focused on the beaker at $15 \mathrm{~cm}$ distance. All of the experiments were performed under natural $\mathrm{pH}$ conditions (around 7-7.5) unless specified otherwise. Then, $3 \mathrm{~mL}$ of the mixture was withdrawn at certain time intervals and centrifuged to remove the MIL-101 solid. The RBB concentration was monitored by means of spectroscopy at the maximum wavelength $(\lambda=600 \mathrm{~nm})$. The experiments were replicated three times.

The chemical oxygen demand (COD) of the RBB solution was measured by the ASTM method [35]. The sample was oxidized by the boiling mixture of chromic and sulfuric acids. The sample was refluxed in a strongly acidic solution with a known excess of potassium dichromate $\left(\mathrm{K}_{2} \mathrm{Cr}_{2} \mathrm{O}_{7}\right)$. After digestion, the remaining unreduced $\mathrm{K}_{2} \mathrm{Cr}_{2} \mathrm{O}_{7}$ was titrated with ferrous ammonium sulfate to determine the amount of $\mathrm{K}_{2} \mathrm{Cr}_{2} \mathrm{O}_{7}$ consumed and the oxidizable matter 


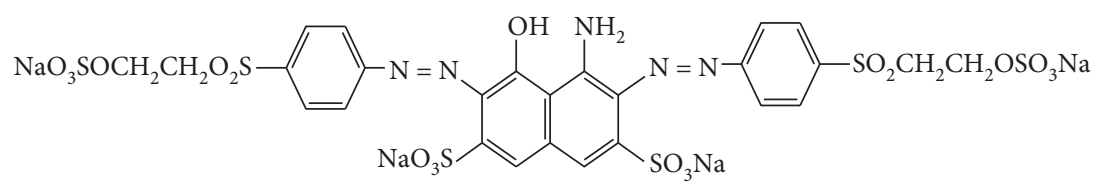

SCHEME 1: Structure of RBB.

was calculated in terms of the oxygen equivalent. The samples were analyzed in duplicate to yield reliable data.

X-ray diffraction (XRD) was carried on a D8 ADVANCE system (Bruker, Germany) (Hanoi city, Vietnam). Cu K $\alpha$ radiation $(\lambda=1.5406 \AA)$ was the light source with applied voltage of $35 \mathrm{kV}$ and current of $40 \mathrm{~mA}$. Transmission electron microscopy (TEM) was carried out using a JEOL JEM2100F microscope (Hanoi city, Vietnam). Nitrogen adsorption/desorption isotherm measurements were conducted using a Micromeritics 2020 volumetric adsorption analyzer system (Hanoi city, Vietnam). The samples were pretreated by heating under vacuum at $150^{\circ} \mathrm{C}$ for $3 \mathrm{~h}$. The BET (Brunauer-Emmett-Teller) model was used to calculate the specific surface area using adsorption data in the relative range $0-0.24$. Total volume was obtained from the nitrogen volume adsorbed at a relative pressure of 0.99 . The X-ray photoelectron spectroscopy (XPS) was conducted using a Shimadzu Kratos AXIS Ultra DLD spectrometer (Japan). Peak fitting was performed by CasaXPS software. The absorbance of $\mathrm{RBB}$, methyl orange (MO), and methylene blue $(\mathrm{MB})$ was measured at $\lambda_{\max }=600 \mathrm{~nm}, 464 \mathrm{~nm}$, and $664 \mathrm{~nm}$, respectively, using a Lambda 25 Spectrophotometer, PerkinElmer, Singapore (Hue city, Vietnam).

\section{Results and Discussion}

3.1. Synthesis of MIL-101 and Its Stability under Different Conditions. The XRD patterns of the MIL-101 samples synthesized with different $\mathrm{Cr} / \mathrm{H}_{2} \mathrm{BDC}$ molar ratios of 0.50 , 0.75, 0.85, 1.00, 1.25, and 1.75 are shown in Figure 1(a). From the figure, it is found that the diffraction at a small angle of about $1.7^{\circ}$ characterizing the mesoporous structure of MIL101 was obtained depending on the $\mathrm{Cr} / \mathrm{H}_{2} \mathrm{BDC}$ ratio. At a low $\mathrm{Cr} / \mathrm{H}_{2} \mathrm{BDC}$ ratio, the diffraction at such a small angle was not observed. However, when the $\mathrm{Cr} / \mathrm{H}_{2} \mathrm{BDC}$ ratio was increased to a level such as M-1.25, M-1.5, or M-1.75, the XRD patterns were similar to the patterns of MIL-101 as reported earlier [22], in which sharp and strong diffraction at $2 \theta$ of around $1.7^{\circ}$ was clearly observed. Therefore, a $\mathrm{Cr} / \mathrm{H}_{2} \mathrm{BDC}$ ratio larger than 1.25 could provide MIL-101 with high crystallinity. The textural properties of MIL-101 samples synthesized at different ratios of $\mathrm{Cr} / \mathrm{H}_{2} \mathrm{BDC}$ were investigated by the $\mathrm{N}_{2}$ adsorption-desorption isotherms at $77 \mathrm{~K}$ as shown in Figure 1(b). The isothermal curves are of type IV, with pore-filling steps at $p / p^{0} \approx 0.2$ and $p / p^{0} \approx 0.3$, characteristic of the presence of two types of narrow mesopores [18]. The parameters characterizing the textural properties of the obtained MIL-101 samples are displayed in Table 1. The specific surface area tends to increase with the increase in the molar ratio of $\mathrm{Cr} / \mathrm{H}_{2} \mathrm{BDC}$ and reaches the highest value at the ratio of 1.25 and then decreases when this ratio continues to rise.

The morphologies of MIL-101 samples synthesized with different molar ratios of $\mathrm{Cr} / \mathrm{H}_{2} \mathrm{BDC}$ were observed by TEM images (Figure 2). It can be seen that the particles have an octahedron shape with different sizes, in the range of 230$570 \mathrm{~nm}$, depending on the molar ratios of $\mathrm{Cr} / \mathrm{H}_{2} \mathrm{BDC}$. The values of standard deviation (SD)/mean (4\%-9\%) were less than $10 \%$ in all cases indicating that particle size distributions were normal. The size of particles reaches a minimum at the $\mathrm{Cr} / \mathrm{H}_{2} \mathrm{BDC}$ ratio of 1.25 (M-1.25) (see Table 1 ). In fact, the effect of the $\mathrm{Cr} / \mathrm{H}_{2} \mathrm{BDC}$ ratio on the MIL-101 particle size was not clear as the $\mathrm{Cr} / \mathrm{H}_{2} \mathrm{BDC}$ ratio was between 0.75 and 1.25. The particle size increased significantly as the $\mathrm{Cr} / \mathrm{H}_{2} \mathrm{BDC}$ ratio is larger than 1.25 . On the contrary, crystallite sizes obtained from the Scherrer equation (using (375) diffraction) was within 34.1 and $45.8 \mathrm{~nm}$ and they appeared to be less affected by the $\mathrm{Cr} / \mathrm{H}_{2} \mathrm{BDC}$ ratio. These results implied that particles consisted of several crystals. Based on the specific surface area and morphology, the suitable $\mathrm{Cr} / \mathrm{H}_{2} \mathrm{BDC}$ molar ratio for the synthesis of MIL-101 was found to be 1.25 .

Figure 3(a) displays the XRD results of MIL-101 samples synthesized with different molar ratios of $\mathrm{H}_{2} \mathrm{O} / \mathrm{H}_{2} \mathrm{BDC}$. The results show that the amount of water in the composition of reactants has a considerable effect on the structure of MIL-101. All the samples with an increase in molar ratios of $\mathrm{H}_{2} \mathrm{O} / \mathrm{H}_{2} \mathrm{BDC}$ from 200 to 700 provided the characteristic diffractions of MIL-101. However, the peak at $2 \theta$ of about $1.7^{\circ}$ characterizing the mesoporous structure did not appear for the samples having a high water content (M-500, M-700), while the same was observed clearly for the samples having a lower water content with molar ratios of $\mathrm{H}_{2} \mathrm{O} / \mathrm{H}_{2} \mathrm{BDC}$ from 200 to 400. In addition, at a high water content in the reactant mixtures, a lower peak intensity was observed. Therefore, the water content in the reactant mixtures not only affected the structure of materials but also reduced their crystallinity.

The isotherms of nitrogen adsorption/desorption and texture properties of MIL-101 synthesized with different molar ratios of $\mathrm{H}_{2} \mathrm{O} / \mathrm{H}_{2} \mathrm{BDC}$ are illustrated in Figure 3(b) and Table 2. It was found that the specific surface area increased steadily when the molar ratio of $\mathrm{H}_{2} \mathrm{O} / \mathrm{H}_{2} \mathrm{BDC}$ increased and peaked at the molar ratio of 350 , but after that, it decreased when this ratio was increased. The water content in the reactant mixtures had a significant effect on the particle size of MIL-101 but had less effect on crystallite size. It can be seen in Figure 4 and Table 2 that the particle size decreased slightly with the increase in water content while crystallite sizes around $26.8-31.8 \mathrm{~nm}$ seemed to be 


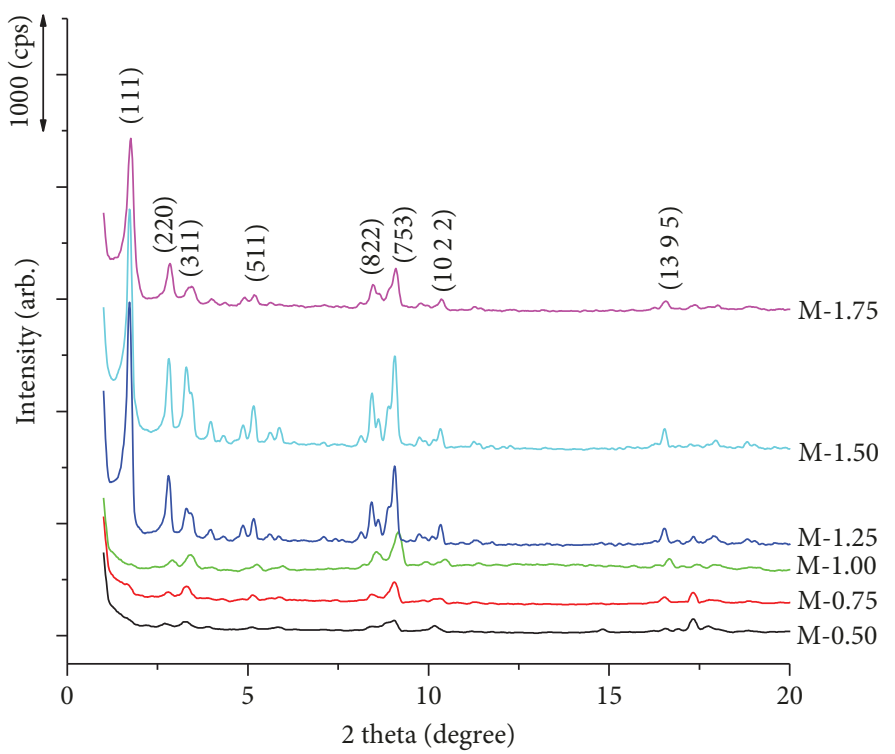

(a)

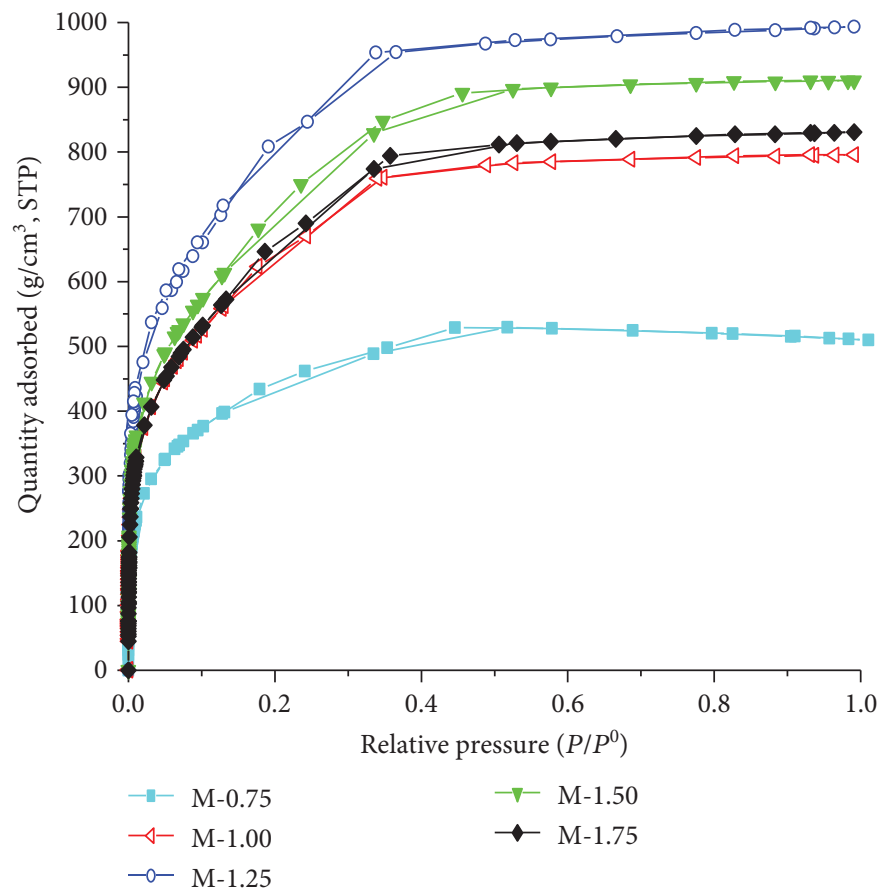

(b)

FIGURE 1: (a) XRD patterns and (b) nitrogen adsorption/desorption isotherms of MIL-101 synthesized using different molar ratios of $\mathrm{Cr} / \mathrm{H}_{2} \mathrm{BDC}$.

unchangeable. A large amount of water resulted in irregular shapes and formation of the needle-shaped crystals of terephthalate acid. It can be inferred that a high water content probably reduced the crystal growth rates [36]. Therefore, a perfect MIL-101 crystal could not be achieved at high water contents in the reactant mixture, and the most perfect MIL-101 crystal was observed in the M350 sample.

As mentioned previously, a larger amount of nonreacted $\mathrm{H}_{2} \mathrm{BDC}$ is present in MIL-101, resulting in a decrease in its surface area and pore volume. The previous studies are focused on the purification using hot ethanol, water, or fluoride-anion exchange using aqueous $\mathrm{NH}_{4} \mathrm{~F}$ solutions $[18,22$, 32]. In the present work, we proposed the Soxhlet extraction using ethanol solvent to purify the $\mathrm{H}_{2} \mathrm{BDC}$. Table 3 shows the specific surface area and porous volume of the present MIL-101 material compared to some previous studies. The surface area and porous volume of MIL-101 synthesized in this study are smaller than those reported by Férey et al. [22] but much higher than recent studies. The proposed purification is time-consuming but is capable for completely 
TABLE 1: Textural properties of MIL-101 samples synthesized using different molar ratios of $\mathrm{Cr} / \mathrm{H}_{2} \mathrm{BDC}$.

\begin{tabular}{lccccc}
\hline Samples & $S_{\text {BET }}\left(\mathrm{m}^{2} \cdot \mathrm{g}^{-1}\right)$ & $S_{\text {Langmuir }}\left(\mathrm{m}^{2} \cdot \mathrm{g}^{-1}\right)$ & $V_{\text {pore }}\left(\mathrm{cm}^{3} \cdot \mathrm{g}^{-1}\right)$ & \multicolumn{2}{c}{$\begin{array}{c}\text { Particle size* } \\
\mathrm{M} \pm \mathrm{SD} \\
(\mathrm{nm})\end{array}$} \\
\hline M-0.75 & 1582 & 2426 & 0.79 & $231.5 \pm 20.1$ & $\begin{array}{c}\text { Crystallite size** } \\
(\mathrm{nm})\end{array}$ \\
M-1.00 & 2328 & 3833 & 1.23 & $376 \pm 15.4$ & 29.3 \\
M-1.25 & 2946 & 4776 & 1.53 & $216 \pm 20.3$ & 43.7 \\
M-1.50 & 2642 & 4354 & 1.41 & $522 \pm 20.0$ & 45.8 \\
M-1.75 & 2414 & 4057 & 1.28 & $573 \pm 27.2$ & 34.6 \\
\hline
\end{tabular}

${ }^{*}$ Mean value $(\mathrm{M})$ of particle size counted from 100 particles. SD: standard deviation. ${ }^{* *}$ Crystallite size calculated from the Scherrer equation using diffraction (753).

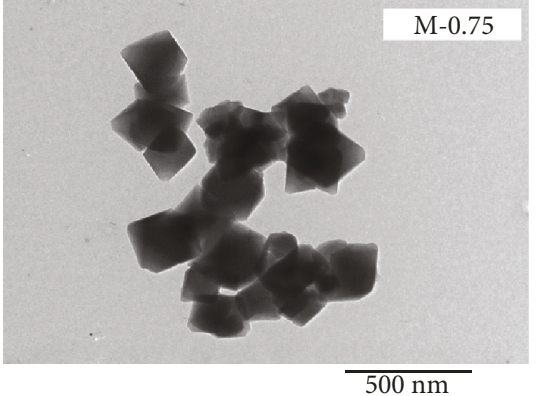

(a)

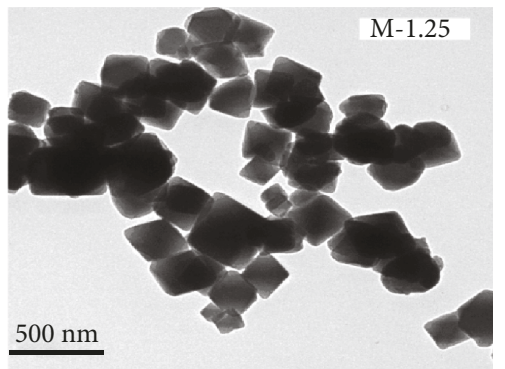

(c)

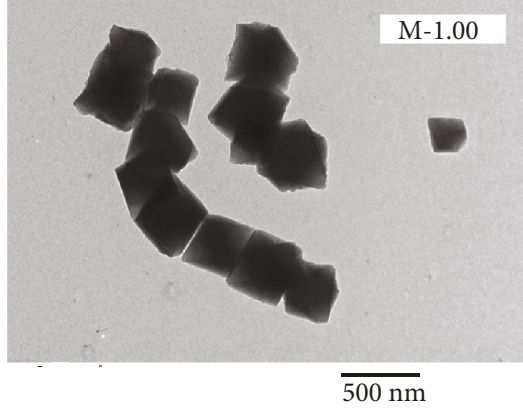

(b)

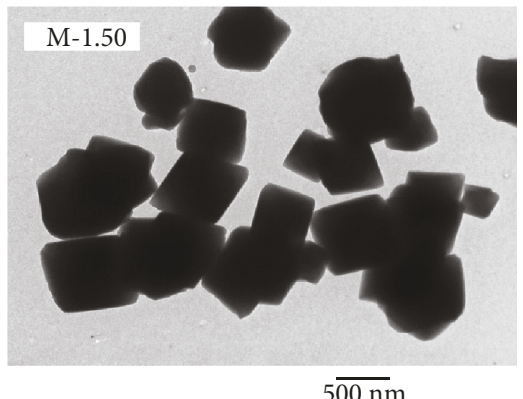

(d)

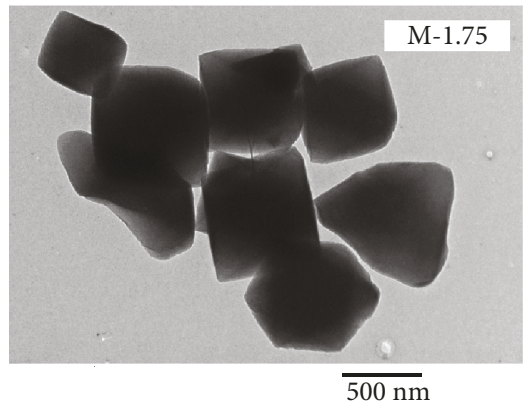

(e)

FIGURE 2: TEM images of MIL-101 synthesized using different molar ratios of $\mathrm{Cr} / \mathrm{H}_{2} \mathrm{BDC}$.

removing $\mathrm{H}_{2} \mathrm{BDC}$, making the obtained MIL-101 have a high specific surface area.

The results of stability testing of MIL-101 under ambient conditions over several days are given in Figures 5(a) and 5(b). Generally, the main characteristic peaks of MIL-101 could be observed in all XRD patterns. The peak at a small angle $\left(2 \theta\right.$ is about $\left.1.7^{\circ}\right)$ was not present in the samples exposed to ambient conditions for 15 to 30 days without drying before XRD measurements (Figure 5(a)). It is worth noting that this peak was observed clearly in the dried sample, 


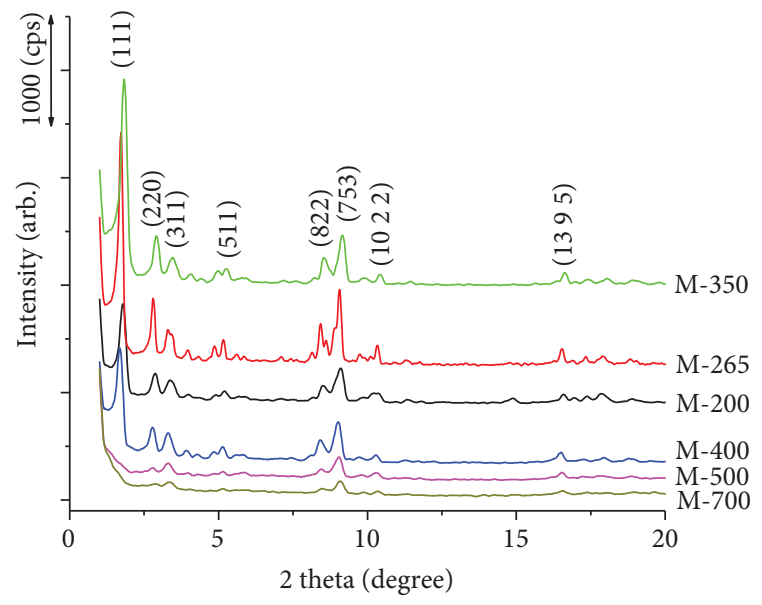

(a)

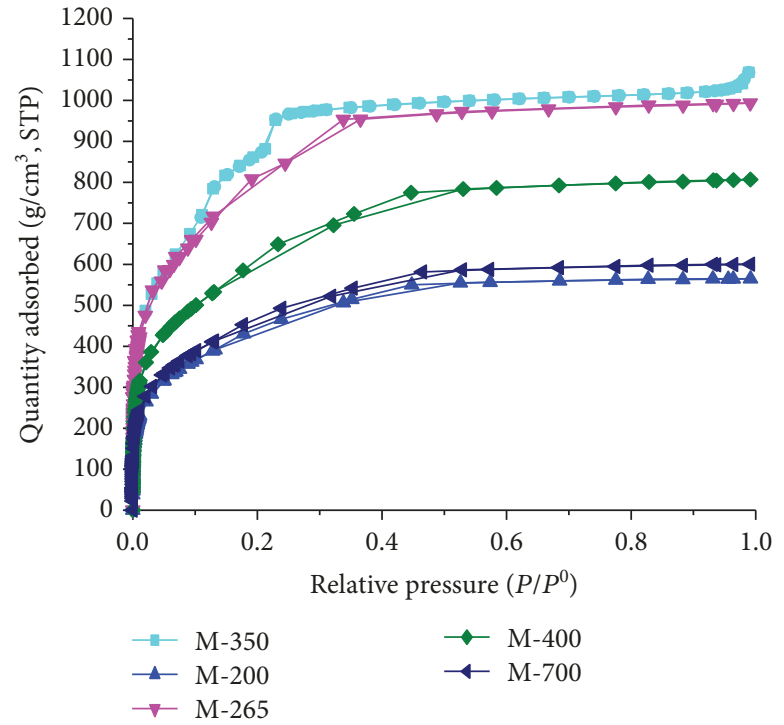

(b)

FIGURE 3: (a) XRD patterns and (b) isotherms of nitrogen adsorption/desorption of MIL-101 synthesized using different molar ratios of $\mathrm{H}_{2} \mathrm{O} / \mathrm{H}_{2} \mathrm{BDC}$.

TABLE 2: Textural properties of MIL-101 samples synthesized using different molar ratios of $\mathrm{H}_{2} \mathrm{O} / \mathrm{H}_{2} \mathrm{BDC}$.

\begin{tabular}{lccccc}
\hline Samples & $S_{\text {BET }}\left(\mathrm{m}^{2} \cdot \mathrm{g}^{-1}\right)$ & $S_{\text {Langmuir }}\left(\mathrm{m}^{2} \cdot \mathrm{g}^{-1}\right)$ & $V_{\text {pore }}\left(\mathrm{cm}^{3} \cdot \mathrm{g}^{-1}\right)$ & $\begin{array}{c}\text { Particle size* } \\
\mathrm{M} \pm \text { SD }(\mathrm{nm})\end{array}$ & Crystallite size $^{* * *}(\mathrm{~nm})$ \\
\hline M-200 & 1618 & 2570 & 0.87 & $530.5 \pm 78.2$ & 26.8 \\
M-265 & 2946 & 4776 & 1.53 & $520.3 \pm 53.4$ & 30.4 \\
M-350 & 3360 & 5059 & 1.44 & $490.3 \pm 19.4$ & 31.8 \\
M-400 & 2274 & 3664 & 1.25 & $250 \pm 35$ & 31.4 \\
M-700 & 1708 & 2701 & 0.93 & $137 \pm 25$ & 30.0 \\
\hline
\end{tabular}

${ }^{*}$ The mean value $(\mathrm{M})$ of 50 particles counted from TEM images. SD: standard deviation. ${ }^{* *}$ Crystallite size calculated from the Scherrer equation using diffraction (753).

although it was exposed to ambient conditions up to a year (Figure 5(b)). The peak at a small angle characteristic of a mesoporous structure seems to be unstable under moistened air. This explains why this peak which diffracted at $1.7^{\circ}$ has been reported in some studies [22], while not in others [13, $15,18]$. The reason is not clear, but it could be possible that water in the moistened air blocks some of the pores resulting in the disappearance of the characteristic diffraction of the mesoporous structure at around $1.7^{\circ}$. Therefore, this peak was observed after the drying process to remove water vapor from the material structure.

The stability of MIL-101 material in water at room temperature is illustrated in Figure 5(c). The results indicate that the characteristic diffractions of MIL-101 were obtained in all patterns. Notably, the characteristic diffraction of the mesoporous structure at around $1.7^{\circ}$ still remained stable after the sample had been soaked in water for several days.

The stability of MIL-101 material in several solvents at boiling temperature for $8 \mathrm{~h}$ is shown in Figure $5(\mathrm{~d})$. The results of XRD indicate that MIL-101 material was still stable after being soaked in boiling water continuously for $8 \mathrm{~h}$, which is in good agreement with that reported by Hong et al. [18]. Moreover, the characteristic diffraction of MIL101 still appeared with high intensity suggesting that its structure did not collapse after soaking in ethanol and benzene at boiling temperature for $8 \mathrm{~h}$. In contrast, the MOFs that are used mostly, such as MOF-177 and MOF-5, have relatively high thermal and chemical stabilities; they are known to be unstable and to easily decompose in the presence of moisture $[38,39]$. Therefore, MIL-101 is rather stable in both polar and nonpolar solvents at high temperatures, which makes MIL-101 an attractive candidate for various applications and catalysts.

Lin et al. [40] used X-ray absorption near edge structure (XANES) spectroscopy for characterizing the oxidation state of $\mathrm{Cr}$ in the MIL-101 catalyst and found that the chromium atom is in the divalent (Cr(II)) state in the MIL-101 crystals although the source of initial $\mathrm{Cr}$ is $\mathrm{Cr}$ (III) in $\mathrm{Cr}\left(\mathrm{NO}_{3}\right)_{3}$. In the present paper, the surface composition of the MIL-101 sample was analyzed by XPS (Figure 6(a)) and the spectra corresponding to $\mathrm{C}_{1 \mathrm{~s}}$ and $\mathrm{Cr}_{2 \mathrm{p}}$ were collected. The binding energy values of $587 \mathrm{eV}$ for $\mathrm{Cr} 2 \mathrm{p} 1 / 2$ and $576 \mathrm{eV}$ for 


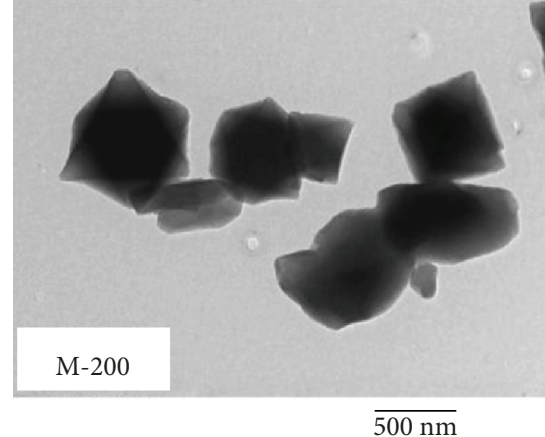

(a)

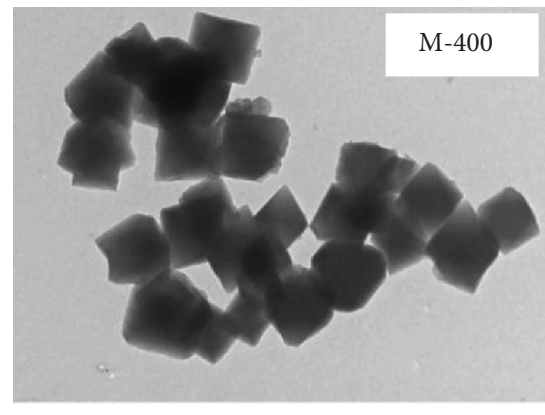

$\overline{500 \mathrm{~nm}}$

(d)

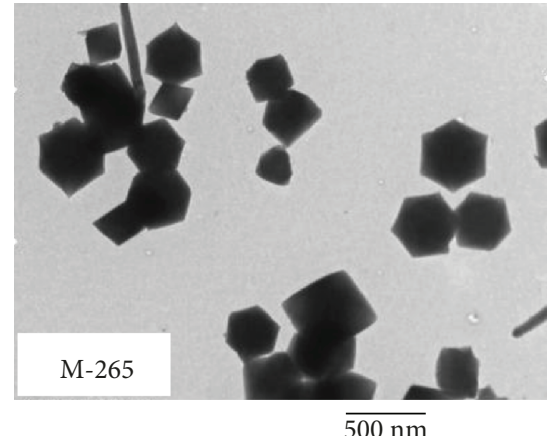

(b)

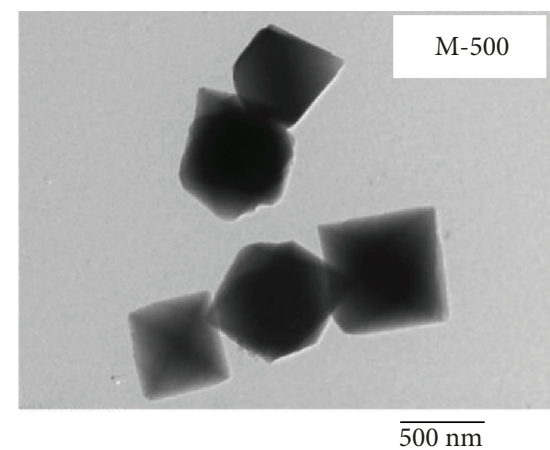

(e)

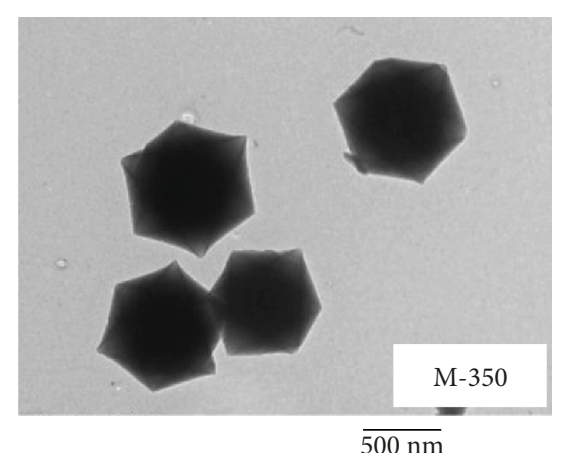

(c)

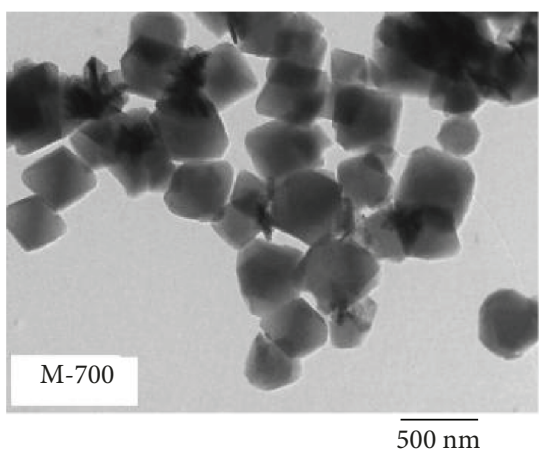

(f)

Figure 4: TEM images of MIL-101 synthesized using different molar ratios of $\mathrm{H}_{2} \mathrm{O} / \mathrm{H}_{2} \mathrm{BDC}$.

Cr2p3/2 (Figure 6(b)) are typically assigned to $\mathrm{Cr}^{3+}[41]$. It could be inferred that the oxidation state Cr(III) of the chromium in MIL-101 does not change during its synthesis.

Figure 7 (a) shows the DR-UV-Vis spectrum of MIL-101. There are three absorption peaks at 275, 425, and $610 \mathrm{~nm}$. The absorption band at the UV region could be contributed by the electron transfer $n \rightarrow \pi^{*}$ in terephthalic acid. The absorption bands in the visible region should be related to the electron transfer in orbital 3d. The energy gaps based on Tauc's plot were found to be $1.75,2.27$, and $3.74 \mathrm{eV}$ (Figure $7(\mathrm{~b})$ ). Since the oxidation state of chromium in MIL-101 is $3+$, it was believed that here the electron shift occurs in the $3 \mathrm{~d}^{3}$ orbital of $\mathrm{Cr}^{3+}$ under the action of the terephthalate ligand field.

In order to analyze this electron transfer, the TanabeSugano $\mathrm{d}^{3}$ diagram was used (Figure 8 ) and, according to which, spin-allowed transition was as follows:

$$
\begin{aligned}
& 4 \mathrm{~A}_{2 \mathrm{~g}} \rightarrow 4 \mathrm{~T}_{2 \mathrm{~g}} \\
& 4 \mathrm{~A}_{2 \mathrm{~g}} \rightarrow 4 \mathrm{~T}_{1 \mathrm{~g}} \\
& 4 \mathrm{~A}_{2 \mathrm{~g}} \rightarrow 4 \mathrm{~T}_{1 \mathrm{~g}}(\mathrm{P})
\end{aligned}
$$

In Tauc's plot (Figure 7), three energy levels could be seen to be excited corresponding to the wave number: $v_{1}=$ $14104.37\left(\mathrm{~cm}^{-1}\right), v_{2}=18281.54\left(\mathrm{~cm}^{-1}\right)$, and $v_{3}=30120.48$ $\left(\mathrm{cm}^{-1}\right)$. Since the ratio $v_{2} / \nu_{1}=18282.54 / 14104.37$ was found as 1.3 , this ratio corresponded to $\Delta_{\mathrm{o}} / B=36$ based on the Tanabe-Sugano diagram of the $\mathrm{d}^{3}$ system ( $\Delta$ is the ligand field splitting parameter). Considering $\Delta_{\mathrm{o}} / B=36$, the value of $E / B$ for the spin-allowed transition was determined to be $v_{1} / B=36, v_{2} / B=46$, and $v_{3} / B=76$.

Since $v_{1}$ was $14104.37 \mathrm{~cm}^{-1}$, the value of $B$ calculated from the first spin-allowed transition was $391.8 \mathrm{~cm}^{-1}$ and $\Delta$ was calculated as $14104.37 \mathrm{~cm}^{-1}$ from the ratio $\Delta / B=36$.

It is worth noting that the Racah $\mathrm{B}$ parameter in MIL101 is $391.8 \mathrm{~cm}^{-1}$ while that in free $\mathrm{Cr}^{3+}$ is $1030 \mathrm{~cm}^{-1}$ [42]. Thus, a reduction of about $62 \%$ in the Racah $\mathrm{B}$ parameter of MIL-101 compared to $\mathrm{Cr}_{2} \mathrm{O}_{3}$ indicates a strong influence of the terephthalate ligand. Figure 8 presents three spin-enabled electrons in the Tanabe-Sugano diagram of the $\mathrm{d}^{3}$ system corresponding to the three excited energy levels as follows:

(i) $4 \mathrm{~A}_{2 \mathrm{~g}} \rightarrow 4 \mathrm{~T}_{2 \mathrm{~g}}$ with energy transfer of $1.75 \mathrm{eV}$ corresponds to a wavelength of $709 \mathrm{~nm}$

(ii) $4 \mathrm{~A} 2 \mathrm{~g} \rightarrow 4 \mathrm{~T}_{1 \mathrm{~g}}$ with energy transfer of $2.27 \mathrm{eV}$ corresponds to a wavelength of $547 \mathrm{~nm}$

(iii) $4 \mathrm{~A} 2 \mathrm{~g} \rightarrow 4 \mathrm{~T}_{1 \mathrm{~g}}(\mathrm{P})$ with energy transfer $3.74 \mathrm{eV}$ corresponds to a wavelength of $332 \mathrm{~nm}$

MIL-101 is constituted from the trimer units $\left(\mathrm{Cr}_{3} \mathrm{O}_{16}\right)$, which are made up of $\mathrm{CrO}_{6}$ clusters, wherein a central chromium atom is surrounded by 6 oxygen atoms [18, 22]. As suggested by Bordiga et al. [43] for MOF-5, it is supposed that $\mathrm{Cr}_{3} \mathrm{O}_{16}$ clusters in MIL-101, which behave as quantum dots surrounded by six terephthalate ligands, could act as light-absorbing antennae $(\mathrm{h} v)$ then transferring it to $\mathrm{Cr}_{3} \mathrm{O}_{16}$ 
TABLE 3: Comparison of the porosity of the present MIL-101 and the results published.

\begin{tabular}{|c|c|c|c|c|}
\hline$S_{\mathrm{BET}}\left(\mathrm{m}^{2} \cdot \mathrm{g}^{-1}\right)$ & $S_{\text {Langmuir }}\left(\mathrm{m}^{2} \cdot \mathrm{g}^{-1}\right)$ & $V\left(\mathrm{~cm}^{3} \cdot \mathrm{g}^{-1}\right)$ & Method/purification & References \\
\hline 3360 & 5059 & 1.4 & Hydrothermal method/Soxhlet extraction using ethanol solvent & The present work \\
\hline 4100 & 5900 & 2.0 & Hydrothermal method/ethanol and DMF & {$[22]$} \\
\hline 4230 & - & 2.2 & $\begin{array}{l}\text { Hydrothermal method/double filtration with glass and paper filters, } \\
\text { water, ethanol, and } \mathrm{NH}_{4} \mathrm{~F}\end{array}$ & {$[18]$} \\
\hline 2345 & 3674 & 1.3 & Microwave-assisted hydrothermal method/ethanol & {$[32]$} \\
\hline 3054 & 4443 & 2. & Microwave-assisted hydrothermal method/ethanol and DMF & {$[37]$} \\
\hline 3197 & 4546 & 1.7 & Solvothermal process/TMAOH $\left(\left(\mathrm{CH}_{3}\right)_{4} \mathrm{NOH}\right)$ & {$[13]$} \\
\hline 2220 & - & 1.1 & Hydrothermal method/ethanol and DMF & {$[20]$} \\
\hline 2674 & - & 1.4 & Hydrothermal method/ethanol and DMF & {$[9]$} \\
\hline 3360 & 4792 & 1.8 & Microwave-assisted hydrothermal method/water, ethanol, and $\mathrm{NH}_{4} \mathrm{~F}$ & {$[15]$} \\
\hline
\end{tabular}

DMF: N,N-dimethylformamide.

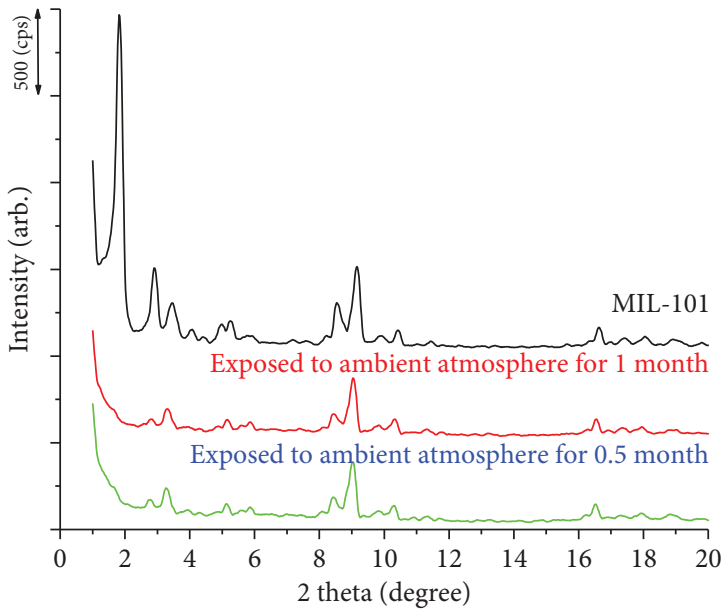

(a)

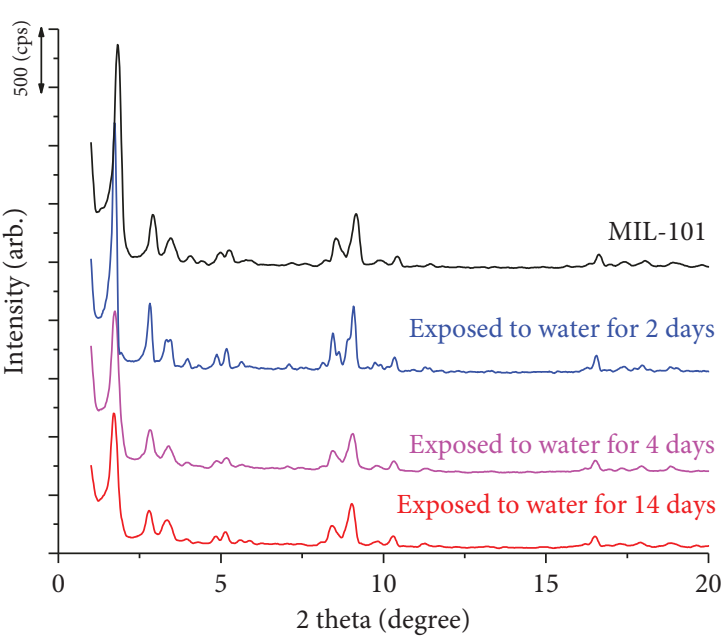

(c)

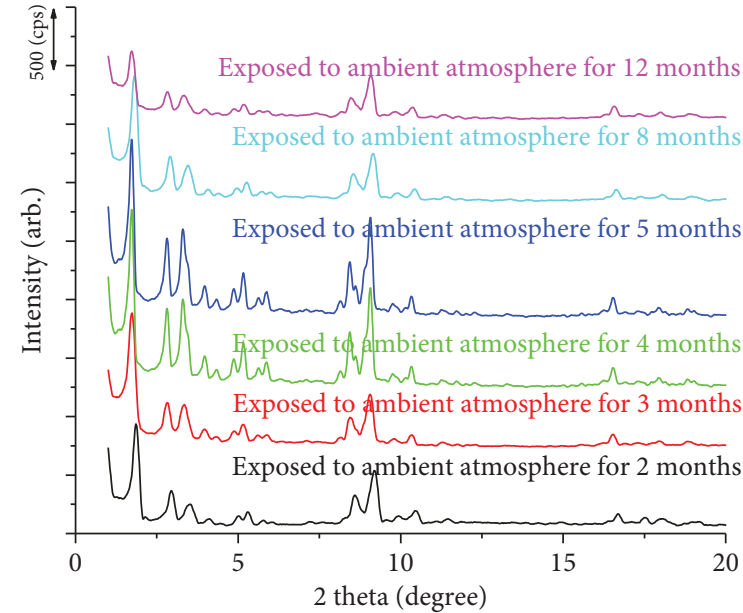

(b)

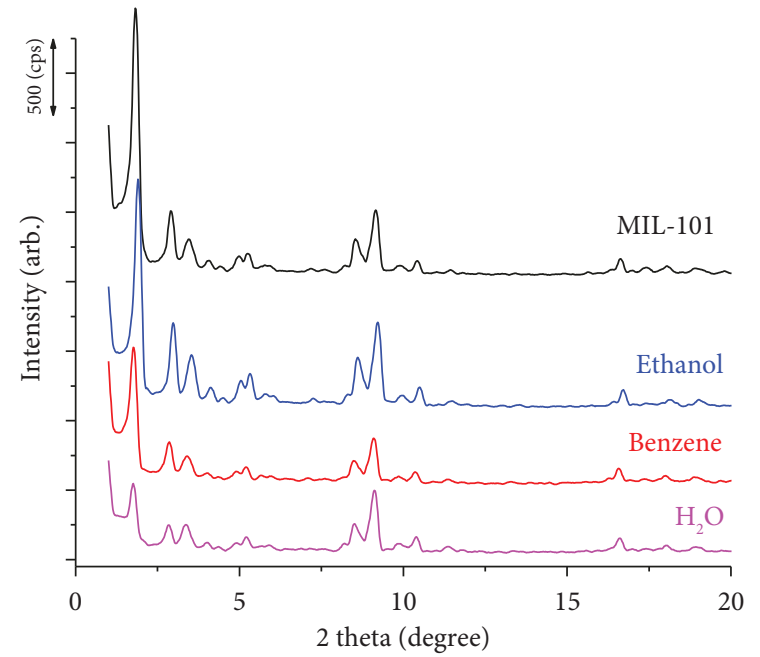

(d)

FIGURE 5: XRD patterns of MIL-101 exposed to ambient atmosphere for several months: (a) MIL-101 sample tested without drying; (b) MIL-101 sample dried at $100^{\circ} \mathrm{C}$ for $12 \mathrm{~h}$ before testing; (c) MIL-101 exposed to water for several days; (d) MIL-101 exposed to several solvents at boiling temperature. 


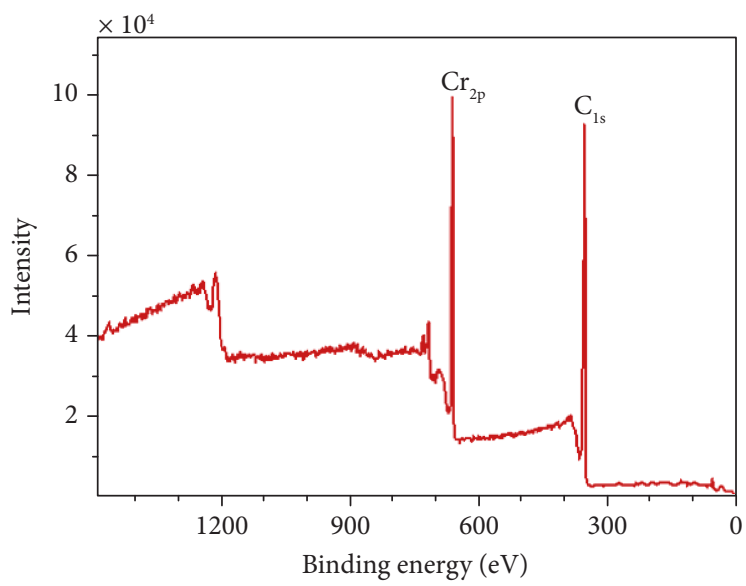

(a)

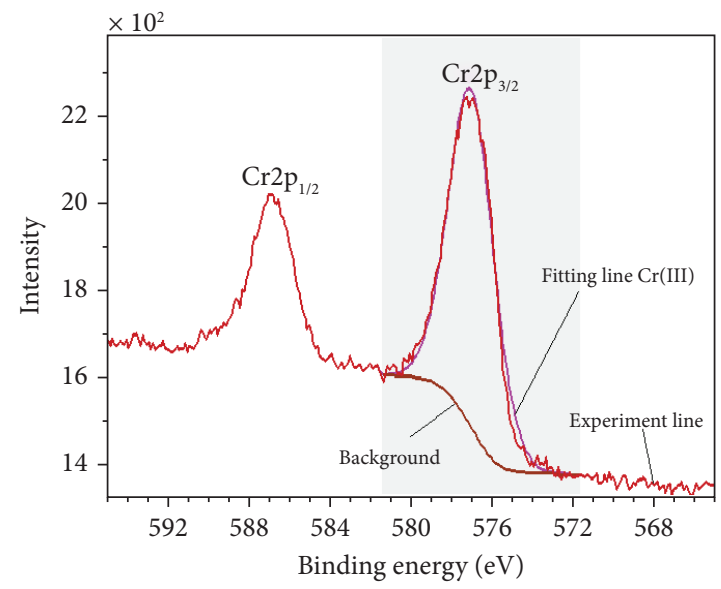

(b)

FIGURE 6: XPS spectra for the MIL-101 (a) and the binding energy of Cr2p (b).

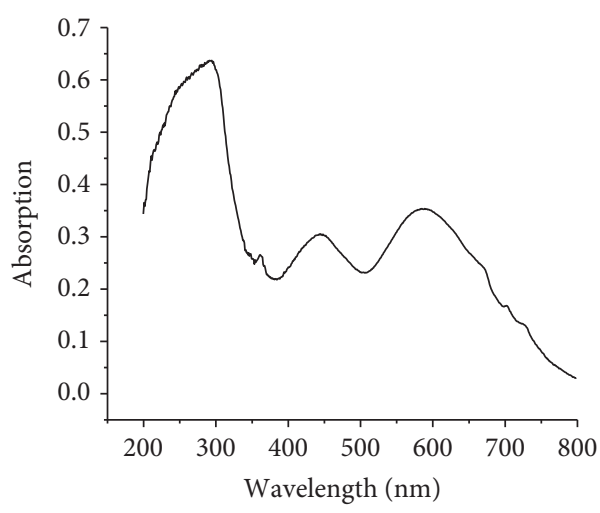

(a)

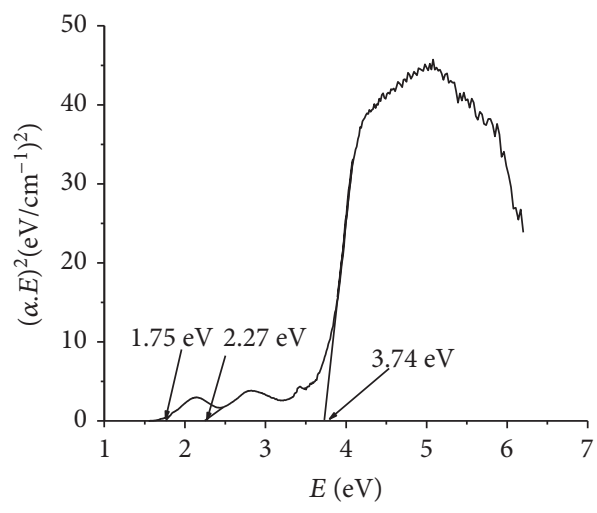

(b)

Figure 7: (a) DR-UV-Vis spectrum; (b) Tauc's plot of MIL-101.

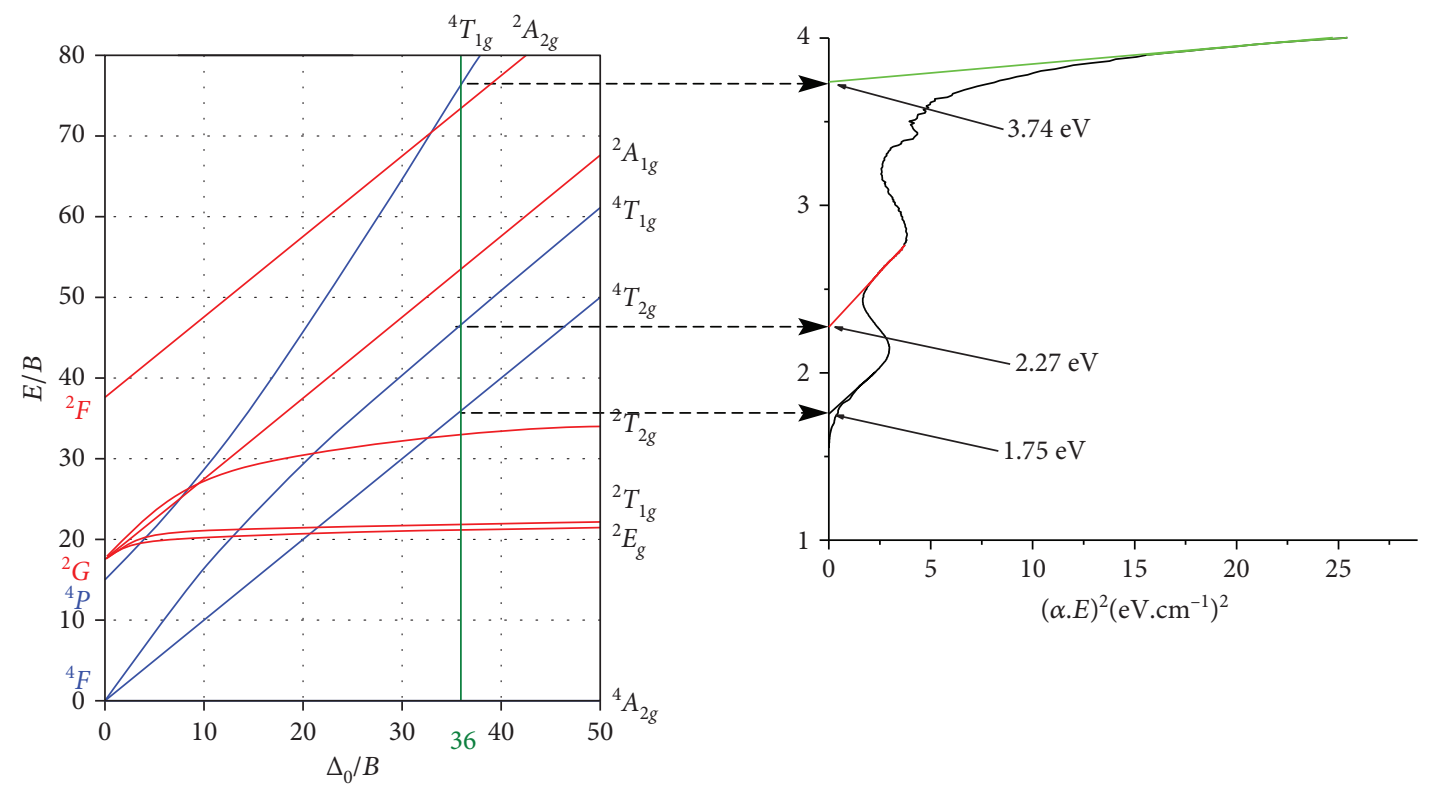

FIGURE 8: The electron shift corresponding to the three excited energy levels in MIL-101. 
clusters to irradiate the photons $\left(\mathrm{h} v^{\prime}\right)$ as can be observed in Figure 9. The photocatalysis of MIL-101 was considered to be achieved by the electron transfer from photoexcited organic ligands to metallic clusters in MIL-101, which was termed as a ligand-to-cluster charge transfer [23, 25].

3.2. Photocatalytic Activity of MIL-101. Adsorption is one of the important aspects of photocatalysis. Hence, in most cases, the dark adsorption is often conducted to obtain an adsorption-desorption equilibrium before UV is irradiated. In the present case, that procedure could not be carried out because the dye molecules were adsorbed quickly on the MIL-101 surface and prevented the UV light from stimulating the MIL-101 catalyst, so that the UV light was irradiated at the same time as the catalyst was introduced as shown in Figure 10. Figure 10(a) shows the decolorization kinetics for $\mathrm{RBB}$ dye under different conditions. It was found that the color of the RBB solution with MIL-101 catalyst but without UV irradiation was decolorized around $43 \%$ within only $15 \mathrm{~min}$ and then stayed constant due to saturated adsorption while the $\mathrm{RBB}$ color was removed completely under UV irradiation/MIL-101 catalysis after $45 \mathrm{~min}$. These experiments demonstrated that the decolorization of the solution was due to the photocatalytic effect rather than adsorption.

The kinetics of decolorization of RBB on MIL-101 added with $0.01 \mathrm{~g} \mathrm{Cr}\left(\mathrm{NO}_{3}\right)_{3}$ or $\mathrm{Cr}_{2} \mathrm{O}_{3}$ are shown in Figure 10 (b). It was found that the $\mathrm{Cr}^{3+}$ ion or $\mathrm{Cr}_{2} \mathrm{O}_{3}$ did not affect decolorization. It could be inferred that the $\mathrm{Cr}^{3+}$ ion or $\mathrm{Cr}_{2} \mathrm{O}_{3}$ does not exhibit photocatalytic activity in this condition. In addition, the decolorization of RBB was not observed if UV was irradiated in the absence of MIL-101 suggesting that RBB was stable and did not undergo photolysis. A leaching experiment was also conducted in which the MIL-101 catalyst was filtered by centrifugation after $5 \mathrm{~min}$ of irradiation. The decolorization of dye was stopped despite the fact that UV light irradiation was still maintained. This indicates that there is no leaching of the active species, into the reaction solution, from the homogeneous catalyst. The above experimental results confirmed that MIL-101 was a heterogeneous catalyst in the degradation reaction of RBB.

The influence of the initial concentration of $\mathrm{RBB}$ on the photocatalytic decolorization rate in the presence of MIL101 is shown in Figure 11. The results exhibited that when the dye concentration increased in the range of $10 \mathrm{ppm}$ to $50 \mathrm{ppm}$, an increase in the decolorization rate was observed.

The generalized rate equation for decolorization of dye can be written as

$$
r=-\frac{d C}{d t}=k \cdot C^{n}
$$

where $C$ is the concentration of dye at time $t$ (the reaction time), $k$ is the kinetic rate constant, $n$ is the order of the reaction, and $r$ is the reaction rate.

In this paper, the initial rate method was used to determine $k$ and $n[44,45]$.

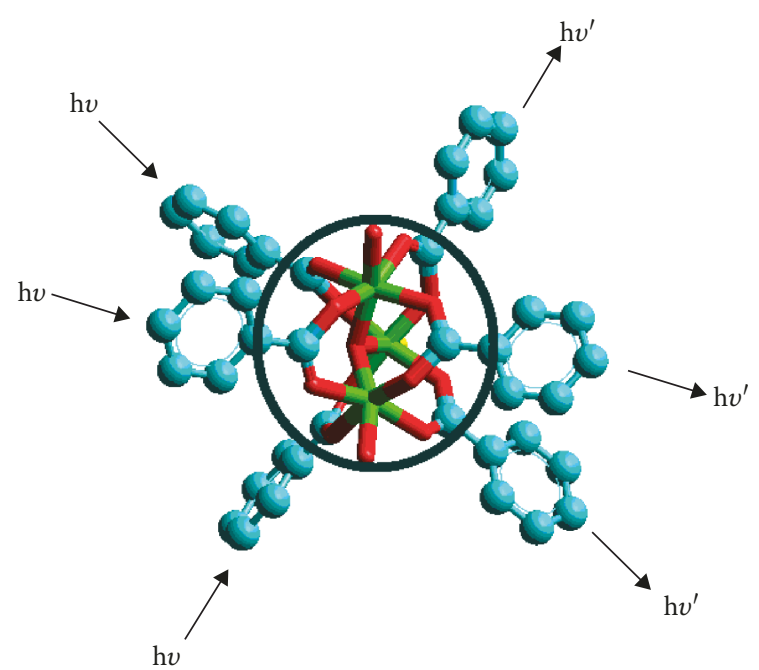

Figure 9: The $\mathrm{Cr}_{3} \mathrm{O}_{16}$ cluster of MIL-101 ( $\mathrm{Cr}$ (green rods), $\mathrm{O}$ (red rods), and benzene ring (blue ring)).

The instantaneous reaction rate was calculated from the following equation:

$$
r_{\text {in }}=-\frac{d C}{d t}
$$

Integrating equation (3) for the boundary conditions $t \rightarrow 0$, then $C \rightarrow C_{0}$ gives

$$
C_{t}=-r_{\text {in }} \cdot t+C_{0},
$$

where $C_{0}$ and $C_{t}$ are the initial concentration and the concentration at time $t$, respectively. The instantaneous rate $\left(r_{\text {in }}\right)$ is determined from the plot of concentration versus time at time $t$. The initial rate $\left(r_{0}\right)$ of a reaction is the instantaneous rate at the start of the reaction (when $t=0$ ). The initial rate is equal to the negative slope of the curve of reactant concentration versus time at $t=0$. From the slopes of the plots of $C_{t}$ against $t$ at $C_{0}(t=0)$, the values of $r_{0}$ corresponding to each initial concentration $C_{0}$ was obtained as shown in Figure 12(a).

On the other hand, the initial rate for a reaction can be written as

$$
r_{0}=k_{i} \cdot C_{0}^{n}
$$

where $k_{i}$ is the overall observed rate constant for the reaction and $n$ is the order of the reaction with respect to the concentration. The linearization of equation (5) by taking natural logarithms on both sizes yields

$$
\ln r_{0}=\ln k_{i}+n \cdot \ln C_{0} .
$$

Therefore, the plot of the $\ln r_{0}$ against $\ln C_{0}$ gives a straight line with a slope corresponding to $n$ and the intercept on the ordinate gives $\ln k_{i}$ (Figure 12(a)). From the plot of $\ln r_{\text {Ao }}$ against $\ln C_{\mathrm{Ao}}$, the slope, $n=0.604$, and $k=1.156$ 


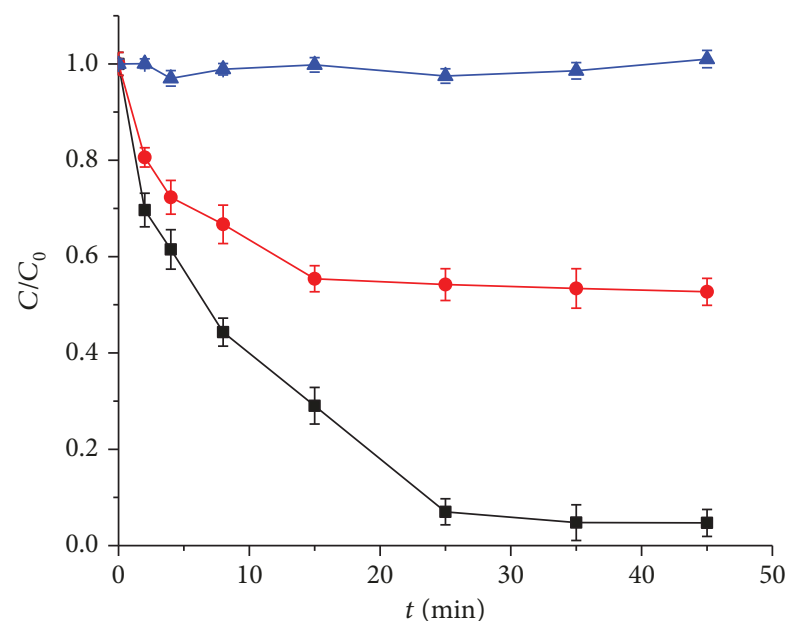

$\rightarrow$ Catalyst with UV irradiation

$\rightarrow$ Catalyst without UV irradiation

- - UV without catalyst

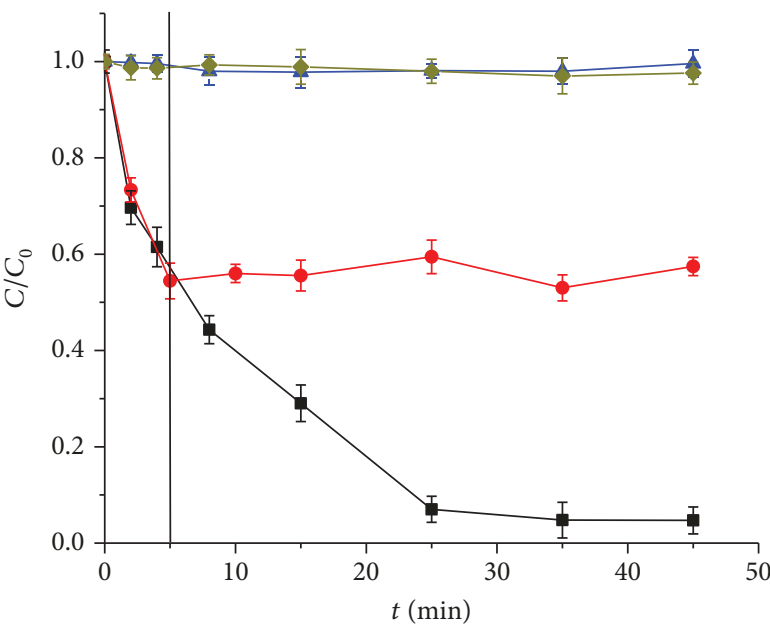

$\rightarrow-$ MIL-101 (Cr) with UV irradiation
$\rightarrow-$ Removing MIL-101 (Cr) after 5 minutes
$-\mathrm{Cr}_{2} \mathrm{O}_{3}$
$\rightarrow-\mathrm{Cr}\left(\mathrm{NO}_{3}\right)_{3}$

(b)

FIgURE 10: (a) The time dependence on decolorization efficiency of the RBB dye with or without MIL-101 catalyst; (b) leaching experiments.

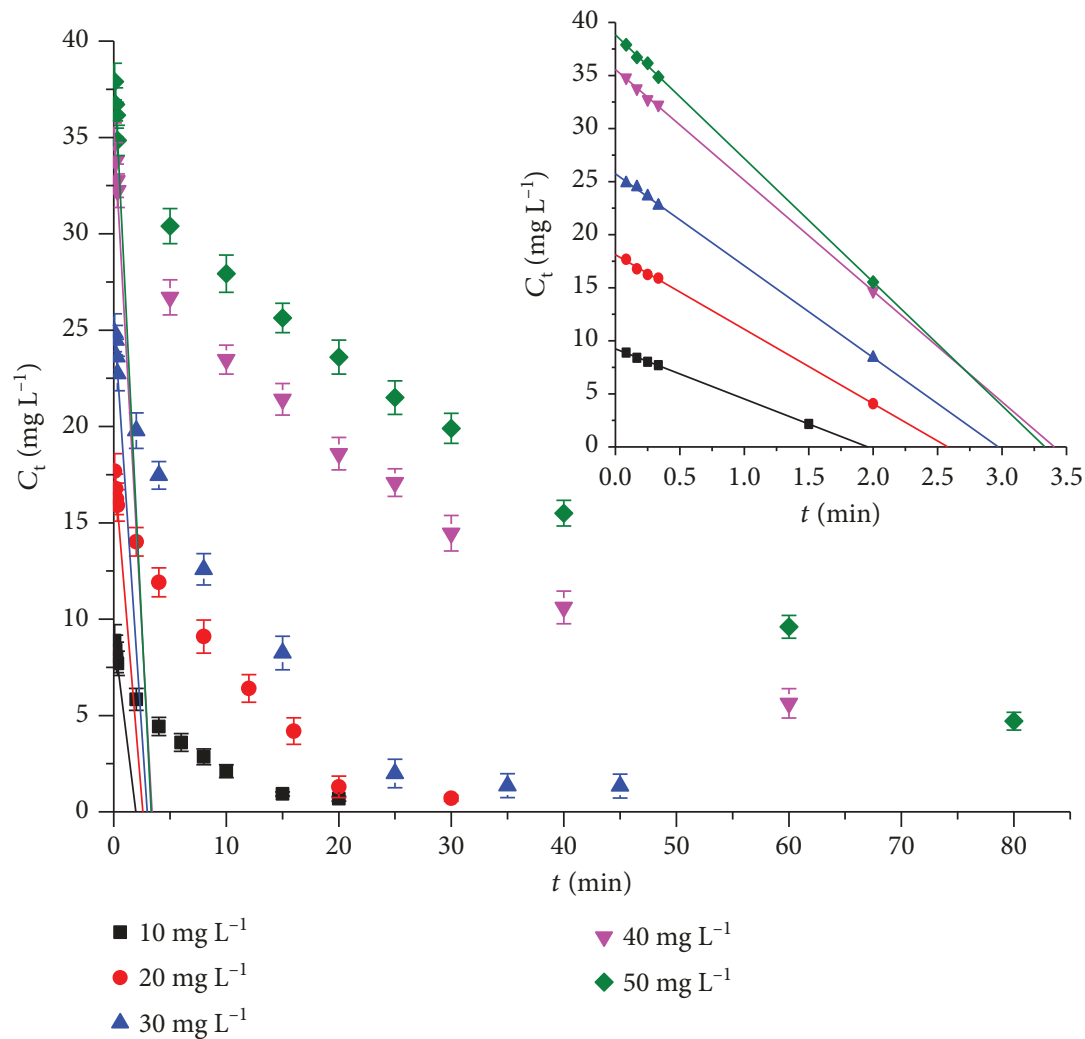

FIgure 11: The plots of $C_{t}$ against $t$ (time) and tangent lines at $C_{0}$; the inset presents extrapolated tangent lines.

were calculated, and the plot has an excellent correlation coefficient $\left(r^{2}=0.998, p \leq 0.001\right)$. The reaction order of photocatalytic degradation is unity in some cases $[27,46]$. In the present paper, the value of $n$ less than unity could be due to the contribution of both adsorption and photocatalytic reaction.

The Langmuir-Hinshelwood (L-H) equation is widely used in studying the kinetics of photocatalytic reaction 


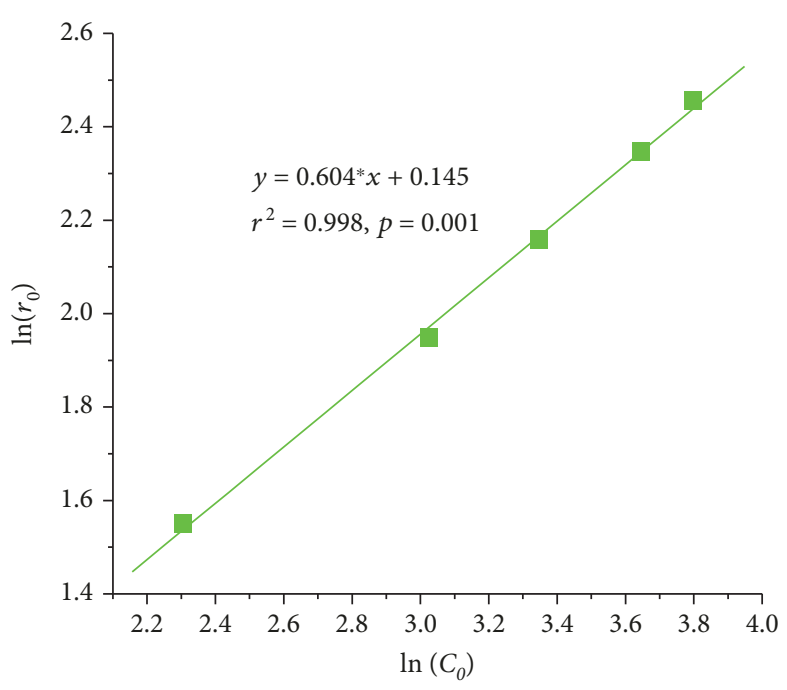

(a)

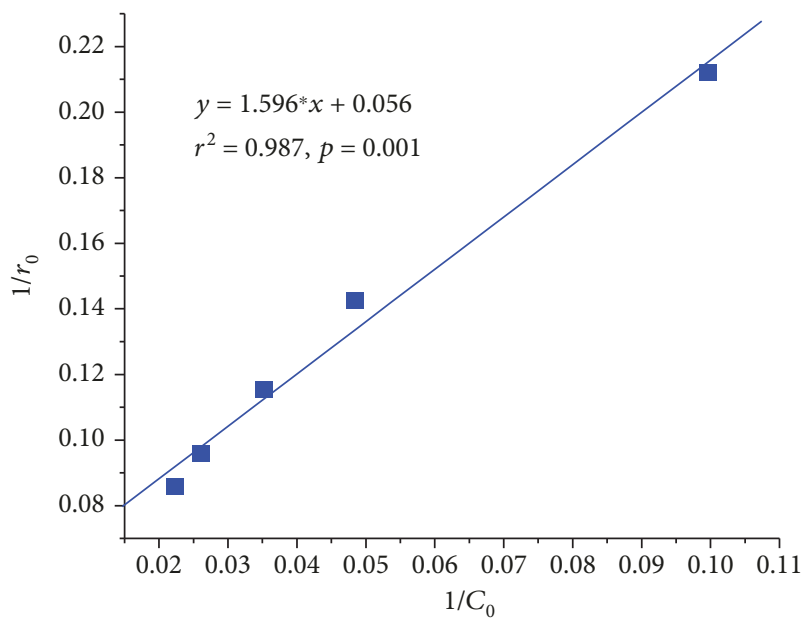

(b)

FIGURE 12: (a) Initial rate plot for RBB to determine the overall rate order; (b) a plot of the Langmuir-Hinshelwood model.

$[46,47]$. In this model, the reaction rate depends on the percentage of the surface coverage, $\theta$, by the following equation:

$$
r_{0}=k_{T} \cdot \theta=-\frac{d C}{d t}=\frac{k_{T} \cdot K_{\mathrm{LH}} \cdot C_{0}}{1+K_{\mathrm{LH}} \cdot C_{0}},
$$

where $K_{\mathrm{LH}}$ is the Langmuir-Hinshelwood adsorption equilibrium constant $\left(\mathrm{L} \cdot \mathrm{mg}^{-1}\right)$ and $k_{T}$ is the reaction rate constant $\left(\mathrm{mg} \cdot \mathrm{L}^{-1} \cdot \mathrm{min}^{-1}\right)$. Equation (7) can be written in the linear form as

$$
\frac{1}{r_{0}}=\frac{1+K_{\mathrm{LH}} \cdot C_{0}}{k_{T} \cdot K_{\mathrm{LH}} \cdot C_{0}}=\frac{1}{k_{T} \cdot K_{\mathrm{LH}} \cdot C_{0}}+\frac{1}{k_{T}} .
$$

The plot of $1 / r_{0}$ against $1 / C_{0}$ (Figure $12(\mathrm{~b})$ ) gives a straight line with a good correlation $\left(r^{2}=0.987, p=0.001\right.$ ); the values of $k_{T}$ and $K_{\mathrm{LH}}$ were $17.857 \mathrm{mg} \cdot \mathrm{L}^{-1} \cdot \mathrm{min}^{-1}$ and $0.035 \mathrm{~L} \cdot \mathrm{mg}^{-1}$, respectively. Akpan and Hameed [46] compared the adsorption and reaction rate relying on the ratio of $k_{T}: K_{\mathrm{LH}}$. However, this comparison seems to be unclear because the units of $k_{T}$ and $K_{\mathrm{LH}}$ are not similar.

The complete degradation of dyes with a cost-effective process is important for industrial applications. UV-Vis spectra are shown in Figure 13(a). The absorbance band at $310 \mathrm{~nm}$ was contributed by the $\pi \rightarrow \pi^{*}$ transition of the double bond in the aromatic ring. The absorbance band at $600 \mathrm{~nm}$ was assigned to $n \rightarrow \pi^{*}$ due to the double bond conjugation of $\mathrm{N}=\mathrm{N}$ and $\mathrm{C}=\mathrm{C}$ in the aromatic ring. The absorption peak decreased significantly with an increase in the irradiation time and disappeared after $45 \mathrm{~min}$ of irradiation. The chemical oxygen demand (COD) test is shown in Figure 13(b). The COD decreased from an initial value of $86.4 \mathrm{mg} \cdot \mathrm{L}^{-1}$ to around $10.0 \mathrm{mg} \cdot \mathrm{L}^{-1}$ after $80 \mathrm{~min}$. The results indicate that $\mathrm{RBB}$ molecules were degraded into fragments and, subsequently, were completed with minerals.
The photochemical degradation mechanism of RBB dye on MIL-101 can be interpreted by the semiconductor theory [25]. As proved earlier, MIL-101 was photoexcited leading to the electron transitions in the $3 \mathrm{~d}^{3}$ orbital, followed by the formation of an electron $\left(\mathrm{e}^{-}\right)$and hole $\left(\mathrm{h}^{+}\right)$pair on the surface of the catalyst. The high oxidation potential of the hole $\left(\mathrm{h}^{+}\right)$in the catalyst either permitted the direct oxidation of the dye or reacted with water molecules or hydroxyl ions $\left(\mathrm{OH}^{-}\right)$to generate hydroxyl radicals $(\mathrm{OH})$. These hydroxyl radicals oxidized the surface adsorbed organic molecules. On the other hand, the photogenerated electrons $\left(\mathrm{e}^{-}\right)$reduced the dye or reacted with the $\mathrm{O}_{2}$ adsorbed on the MIL-101 surface or dissolved in water forming a radical anion $\left(\mathrm{O}_{2}{ }^{-}\right)$. This strong oxidation could degrade RBB. According to this, the photochemical degradation reactions of RBB on MIL-101 can be expressed as follows:

$$
\begin{aligned}
&(\mathrm{MIL}-101)+\mathrm{h} v(\text { MIL-101 })\left(\mathrm{e}^{-}+\mathrm{h}^{+}\right) \\
& \mathrm{h}^{+}+\text {dye } \rightarrow \mathrm{RBB}^{\cdot} \rightarrow \text { degradation products } \\
& \mathrm{h}^{+}+\mathrm{H}_{2} \mathrm{O} \rightarrow \mathrm{H}^{+}+\mathrm{OH} \\
& \mathrm{h}^{+}+\mathrm{OH}^{-} \rightarrow \mathrm{OH} \\
& \mathrm{OH}+\mathrm{RBB}^{\cdot} \rightarrow \text { degradation products } \\
& \mathrm{e}^{-}+\mathrm{O}_{2} \rightarrow \mathrm{O}_{2}^{-} \\
& \mathrm{O}_{2}{ }^{-}+\mathrm{RBB} \rightarrow \text { degradation products }
\end{aligned}
$$

The reusability of the catalyst is an important concern in the application of heterogeneous catalysis. After the experiment, the MIL-101 material was collected by centrifugation and washed with water and ethanol for three times to remove $\mathrm{RBB}$ completely and dried at $120^{\circ} \mathrm{C}$ for $15 \mathrm{~h}$ and then reused. The photocatalytic degradation efficiency of MIL-101 after four cycles of usage was decreased slightly 


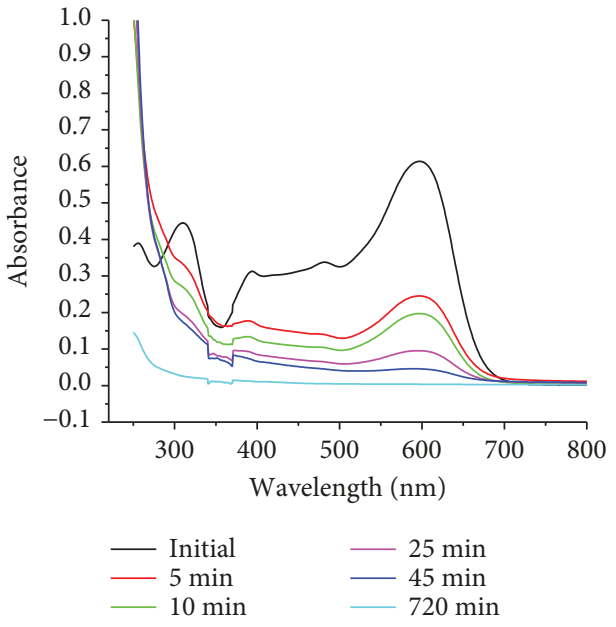

(a)

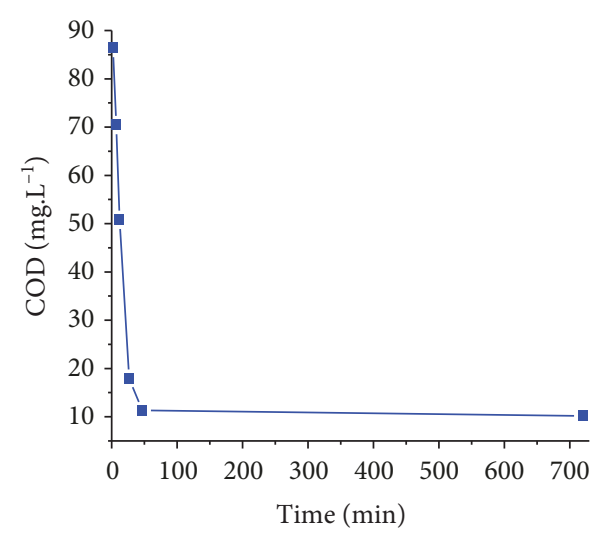

(b)

Figure 13: The UV-Vis spectrum (a) and the chemical oxygen demand (COD) test (b) of the RBB dye and RBB degradation over MIL101(Cr) under UV irradiation.

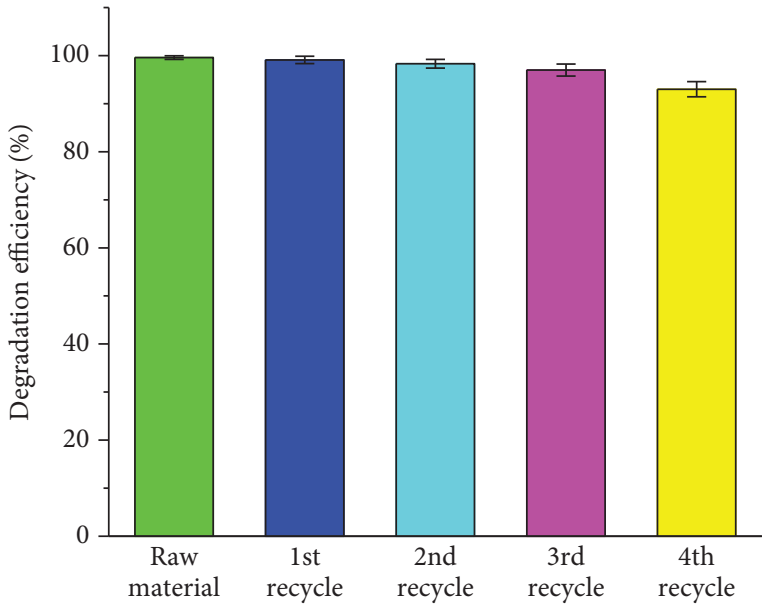

(a)

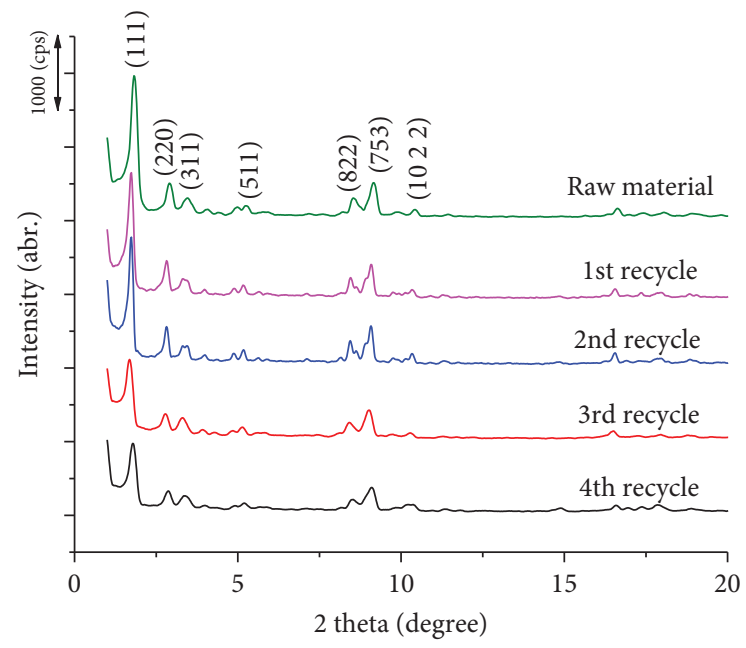

(b)

FIGURE 14: (a) The RBB degradation efficiency of the MIL-101 photocatalyst for the fourth cycle; (b) XRD patterns of MIL-101 and used MIL$101\left(V=450 \mathrm{~mL} ; C_{0}=90 \mathrm{mg} \cdot \mathrm{L}^{-1}\right.$, UV-irradiation time: $\left.45 \mathrm{~min}\right)$.

(only 5\%) (Figure 14(a)). The XRD patterns of the recycled MIL-101 catalysts were unchanged (Figure 14(b)). It can be concluded that the MIL-101 photocatalyst exhibited excellent catalytic recyclability and stability in the tested conditions. It can be inferred that MIL-101 can be a potential catalyst for the treatment of organic pollutants in aqueous solutions.

\section{Conclusions}

The suitable molar ratios of $\mathrm{Cr} / \mathrm{H}_{2} \mathrm{BDC}$ and $\mathrm{H}_{2} \mathrm{O} / \mathrm{H}_{2} \mathrm{BDC}$ for the synthesis of MIL-101 with a large surface area and high crystallinity were 1.25 and 350, respectively. High water content in the synthesized gel significantly reduced particle size and crystallinity. MIL-101 can be exposed to ambient conditions for several months. The characteristic XRD diffraction pattern at $1.7^{\circ}$ can be observed in the samples stored in dry conditions, whereas this diffraction disappeared when the samples were stored in moistened conditions. MIL-101 is stable in water, benzene, and toluene even at boiling point for several hours. MIL-101 exhibited excellent photodegradation of $\mathrm{RBB}$ in the UV region. The kinetics of the photocatalytic degradation reaction was fitted well with the LangmuirHinshelwood (L-H) equation. The initial rate method yielded the order of the reaction and the initial reaction rate constant to be 0.604 and $1.156\left[\left(\mathrm{mg} \cdot \mathrm{L}^{-1}\right)^{0.396} \cdot \mathrm{min}^{-1}\right]$, respectively.

\section{Data Availability}

The data used to support the findings of this study are available from the corresponding author upon request. 


\section{Conflicts of Interest}

The authors declare that they have no conflict of interest.

\section{Acknowledgments}

This research was sponsored by Hue University under Decision No. 1208/QĐ-DHH.

\section{References}

[1] F. P. van der Zee and S. Villaverde, "Combined anaerobicaerobic treatment of azo dyes-a short review of bioreactor studies," Water Research, vol. 39, no. 8, pp. 1425-1440, 2005.

[2] P. A. Soloman, C. A. Basha, M. Velan, V. Ramamurthi, K. Koteeswaran, and N. Balasubramanian, "Electrochemical degradation of Remazol Black B dye effluent," Clean - Soil, Air, Water, vol. 37, no. 11, pp. 889-900, 2009.

[3] M. Thi Thanh, T. Vinh Thien, V. Thi Thanh Chau, P. Dinh Du, N. Phi Hung, and D. Quang Khieu, "Synthesis of iron doped zeolite imidazolate framework-8 and its Remazol deep black RGB dye adsorption ability," Journal of Chemistry, vol. 2017, 18 pages, 2017.

[4] N. F. Cardoso, R. B. Pinto, E. C. Lima et al., "Removal of Remazol Black B textile dye from aqueous solution by adsorption," Desalination, vol. 269, no. 1-3, pp. 92-103, 2011.

[5] V. P. Ranjusha, R. Pundir, K. Kumar, M. G. Dastidar, and T. R. Sreekrishnan, "Biosorption of Remazol Black B dye (azo dye) by the growing Aspergillus flavus," Journal of Environmental Science and Health, Part A, vol. 45, no. 10, pp. 1256-1263, 2010.

[6] M. T. Thanh, T. V. Thien, P. D. Du, N. P. Hung, and D. Q. Khieu, "Iron doped zeolitic imidazolate framework (Fe-ZIF8): synthesis and photocatalytic degradation of RDB dye in Fe-ZIF-8," Journal of Porous Materials, vol. 25, no. 3, pp. 857-869, 2018.

[7] C. Janiak and J. K. Vieth, "MOFs, MILs and more: concepts, properties and applications for porous coordination networks (PCNs)," New Journal of Chemistry, vol. 34, no. 11, pp. 23662388, 2010.

[8] O. M. Yaghi, M. O'Keeffe, N. W. Ockwig, H. K. Chae, M. Eddaoudi, and J. Kim, "Reticular synthesis and the design of new materials," Nature, vol. 423, no. 6941, pp. 705-714, 2003.

[9] P. Chowdhury, C. Bikkina, and S. Gumma, "Gas adsorption properties of the chromium-based metal organic framework MIL-101," Journal of Physical Chemistry C, vol. 113, no. 16, pp. 6616-6621, 2009.

[10] L. Hamon, C. Serre, T. Devic et al., "Comparative study of hydrogen sulfide adsorption in the MIL-53(Al, Cr, Fe), MIL-47(V), MIL-100(Cr), and MIL-101(Cr) metal-organic frameworks at room temperature," Journal of the American Chemical Society, vol. 131, no. 25, pp. 8775-8777, 2009.

[11] Y. Li and R. T. Yang, "Hydrogen storage in metal-organic and covalent-organic frameworks by spillover," AICHE Journal, vol. 54, no. 1, pp. 269-279, 2008.

[12] P. L. Llewellyn, S. Bourrelly, C. Serre et al., "High uptakes of $\mathrm{CO} 2$ and $\mathrm{CH} 4$ in mesoporous metal-organic frameworks MIL-100 and MIL-101," Langmuir, vol. 24, no. 14, pp. 72457250, 2008.

[13] J. Yang, Q. Zhao, J. Li, and J. Dong, "Synthesis of metal-organic framework MIL-101 in TMAOH-Cr( $\left.\mathrm{NO}_{3}\right)_{3}-\mathrm{H}_{2} \mathrm{BDC}-\mathrm{H}_{2} \mathrm{O}$ and its hydrogen-storage behavior," Microporous and Mesoporous Materials, vol. 130, no. 1-3, pp. 174-179, 2010.

[14] K. Yang, Q. Sun, F. Xue, and D. Lin, “Adsorption of volatile organic compounds by metal-organic frameworks MIL-101: influence of molecular size and shape," Journal of Hazardous Materials, vol. 195, pp. 124-131, 2011.

[15] Z. Zhang, S. Huang, S. Xian, H. Xi, and Z. Li, "Adsorption equilibrium and kinetics of $\mathrm{CO}_{2}$ on chromium terephthalate MIL-101," Energy \& Fuels, vol. 25, no. 2, pp. 835842, 2011.

[16] R. Kitaura, K. Seki, G. Akiyama, and S. Kitagawa, "Porous coordination-polymer crystals with gated channels specific for supercritical gases," Angewandte Chemie International Edition, vol. 42, no. 4, pp. 428-431, 2003.

[17] S. Ma, D. Sun, X.-S. Wang, and H.-C. Zhou, "A meshadjustable molecular sieve for general use in gas separation," Angewandte Chemie International Edition, vol. 46, no. 14, pp. 2458-2462, 2007.

[18] D. Y. Hong, Y. K. Hwang, C. Serre, G. Férey, and J. S. Chang, "Porous chromium terephthalate MIL-101 with coordinatively unsaturated sites: surface functionalization, encapsulation, sorption and catalysis," Advanced Functional Materials, vol. 19, no. 10, pp. 1537-1552, 2009.

[19] Y. K. Hwang, D. Y. Hong, J. S. Chang et al., "Selective sulfoxidation of aryl sulfides by coordinatively unsaturated metal centers in chromium carboxylate MIL-101," Applied Catalysis A: General, vol. 358, no. 2, pp. 249-253, 2009.

[20] N. Maksimchuk, M. Timofeeva, M. Melgunov et al., "Heterogeneous selective oxidation catalysts based on coordination polymer MIL-101 and transition metal-substituted polyoxometalates," Journal of Catalysis, vol. 257, no. 2, pp. 315-323, 2008.

[21] Z. Saedi, S. Tangestaninejad, M. Moghadam, V. Mirkhani, and I. Mohammadpoor-Baltork, "MIL-101 metal-organic framework: a highly efficient heterogeneous catalyst for oxidative cleavage of alkenes with $\mathrm{H}_{2} \mathrm{O}_{2}$," Catalysis Communications, vol. 17, pp. 18-22, 2012.

[22] G. Férey, C. Mellot-Draznieks, C. Serre et al., “A chromium terephthalate-based solid with unusually large pore volumes and surface area," Science, vol. 309, no. 5743, pp. 2040-2042, 2005.

[23] J. Gascon, M. D. Hernández-Alonso, A. R. Almeida, G. P. M. van Klink, F. Kapteijn, and G. Mul, "Isoreticular MOFs as efficient photocatalysts with tunable band gap: an operando FTIR study of the photoinduced oxidation of propylene," ChemSusChem, vol. 1, no. 12, pp. 981-983, 2008.

[24] C. G. Silva, A. Corma, and H. García, "Metal-organic frameworks as semiconductors," Journal of Materials Chemistry, vol. 20, no. 16, pp. 3141-3156, 2010.

[25] F. X. Llabre, A. Corma, H. Garcia, D. Valencia, and C. De Vera, "Applications for metal-organic frameworks (MOFs) as quantum dot semiconductors," Journal of Physical Chemistry C, vol. 111, pp. 80-85, 2006.

[26] Q. Xu, Y. Wang, G. Jin et al., "Photooxidation assisted sensitive detection of trace $\mathrm{Mn}^{2+}$ in tea by $\mathrm{NH}_{2}$-MIL-125 (Ti) modified carbon paste electrode," Sensors and Actuators B: Chemical, vol. 201, pp. 274-280, 2014.

[27] J. J. Du, Y. P. Yuan, J. X. Sun et al., "New photocatalysts based on MIL-53 metal-organic frameworks for the decolorization of methylene blue dye," Journal of Hazardous Materials, vol. 190, no. 1-3, pp. 945-951, 2011. 
[28] N. V. Maksimchuk, K. A. Kovalenko, V. P. Fedin, and O. A. Kholdeeva, "Heterogeneous selective oxidation of alkenes to $\alpha, \beta$-unsaturated ketones over coordination polymer MIL-101," Advanced Synthesis and Catalysis, vol. 352, no. 17, pp. 2943-2948, 2010.

[29] S. J. Lee, J. W. Yoon, Y. K. Seo et al., "Effect of purification conditions on gas storage and separations in a chromium-based metal-organic framework MIL-101," Microporous and Mesoporous Materials, vol. 193, pp. 160-165, 2014.

[30] D. Liu, Y. S. Lin, Z. Li, and H. Xi, "Adsorption and separation of $\mathrm{CH}_{4} / \mathrm{H}_{2}$ in MIL-101s by molecular simulation study," Chemical Engineering Science, vol. 98, pp. 246-254, 2013.

[31] Q. Liu, L. Ning, S. Zheng, M. Tao, Y. Shi, and Y. He, "Adsorption of carbon dioxide by MIL-101(Cr): regeneration conditions and influence of flue gas contaminants," Scientific Reports, vol. 3, no. 1, 2013.

[32] M. S. El-Shall, V. Abdelsayed, A. E. R. S. Khder, H. M. A. Hassan, H. M. El-Kaderi, and T. E. Reich, "Metallic and bimetallic nanocatalysts incorporated into highly porous coordination polymer MIL-101," Journal of Materials Chemistry, vol. 19, no. 41, pp. 7625-7631, 2009.

[33] Y. Xu, Q. Chen, H. Yang et al., "Enhanced photodegradation of rhodamine $\mathrm{B}$ under visible light by $\mathrm{N}-\mathrm{K}_{2} \mathrm{Ti}_{4} \mathrm{O}_{9} / \mathrm{MIL}-101 \mathrm{com}-$ posite," Materials Science in Semiconductor Processing, vol. 36, pp. 115-123, 2015.

[34] M. Lv, H. Yang, Y. Xu, Q. Chen, X. Liu, and F. Wei, "Improving the visible light photocatalytic activities of $\mathrm{Bi}_{25} \mathrm{FeO}_{40} / \mathrm{MIL}-101 / \mathrm{PTH}$ via polythiophene wrapping," Journal of Environmental Chemical Engineering, vol. 3, no. 2, pp. 1003-1008, 2015.

[35] L. S. Clesceri, A. E. Greenberg, and R. R. Trussell, Standard Methods for the Examination of Water and Wastewater, American Public Health Association, 20th edition, 1998.

[36] N. A. Khan, I. J. Kang, H. Y. Seok, and S. H. Jhung, "Facile synthesis of nano-sized metal-organic frameworks, chromium-benzenedicarboxylate, MIL-101," Chemical Engineering Journal, vol. 166, no. 3, pp. 1152-1157, 2011.

[37] Z. Zhao, X. Li, S. Huang, Q. Xia, and Z. Li, "Adsorption and diffusion of benzene on chromium-based metal organic framework MIL-101 synthesized by microwave irradiation," Industrial and Engineering Chemistry Research, vol. 50, no. 4, pp. 2254-2261, 2011.

[38] B. Panella and M. Hirscher, "Hydrogen physisorption in metal-organic porous crystals," Advanced Materials, vol. 17, no. 5, pp. 538-541, 2005.

[39] Y. Li and R. T. Yang, "Gas adsorption and storage in metal -organic framework MOF-177," Langmuir, vol. 23, no. 26, pp. 12937-12944, 2007.

[40] K. S. Lin, A. K. Adhikari, Y. H. Su, C. L. Chiang, and K. Dehvari, "Structural characterization of chromium atoms in MIL-101 metal organic frameworks using XANES/EXAFS spectroscopy," Chinese Journal of Physics, vol. 50, pp. 322342, 2012.

[41] T. Van Vu, H. Kosslick, A. Schulz et al., "Selective hydroformylation of olefins over the rhodium supported large porous metal-organic framework MIL-101," Applied Catalysis A: General, vol. 468, pp. 410-417, 2013.

[42] Q. Wei, "Investigations of the optical and EPR spectra for $\mathrm{Cr}^{3+}$ ions in diammonium hexaaqua magnesium sulphate single crystal," Acta Physica Polonica A, vol. 118, no. 4, pp. 670$672,2010$.
[43] S. Bordiga, C. Lamberti, G. Ricchiardi et al., "Electronic and vibrational properties of a MOF-5 metal-organic framework: $\mathrm{ZnO}$ quantum dot behaviour," Chemical Communications, vol. 5, pp. 2300-2301, 2004.

[44] C. Galindo, P. Jacques, and A. Kalt, "Photooxidation of the phenylazonaphthol $\mathrm{AO}_{20}$ on $\mathrm{TIO}_{2}$ : kinetic and mechanistic investigations," Chemosphere, vol. 45, no. 6-7, pp. 997-1005, 2001.

[45] S. Khezrianjoo, "Langmuir-Hinshelwood kinetic expression for the photocatalytic degradation of metanil yellow aqueous solutions by $\mathrm{ZnO}$ catalyst," Chemical Science, vol. 85, pp. 1-7, 2012.

[46] U. G. Akpan and B. H. Hameed, "Photocatalytic degradation of 2,4-dichlorophenoxyacetic acid by $\mathrm{Ca}-\mathrm{Ce}-\mathrm{W}-\mathrm{TiO}_{2}$ composite photocatalyst," Chemical Engineering Journal, vol. 173, no. 2, pp. 369-375, 2011.

[47] M. Saquib and M. Muneer, " $\mathrm{TiO}_{2} /$ mediated photocatalytic degradation of a triphenylmethane dye (gentian violet), in aqueous suspensions," Dyes and Pigments, vol. 56, no. 1, pp. 37-49, 2003. 


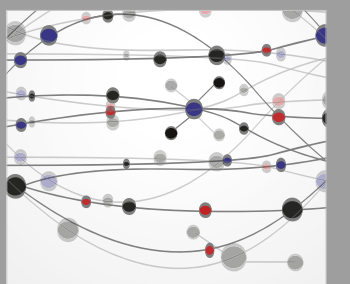

The Scientific World Journal
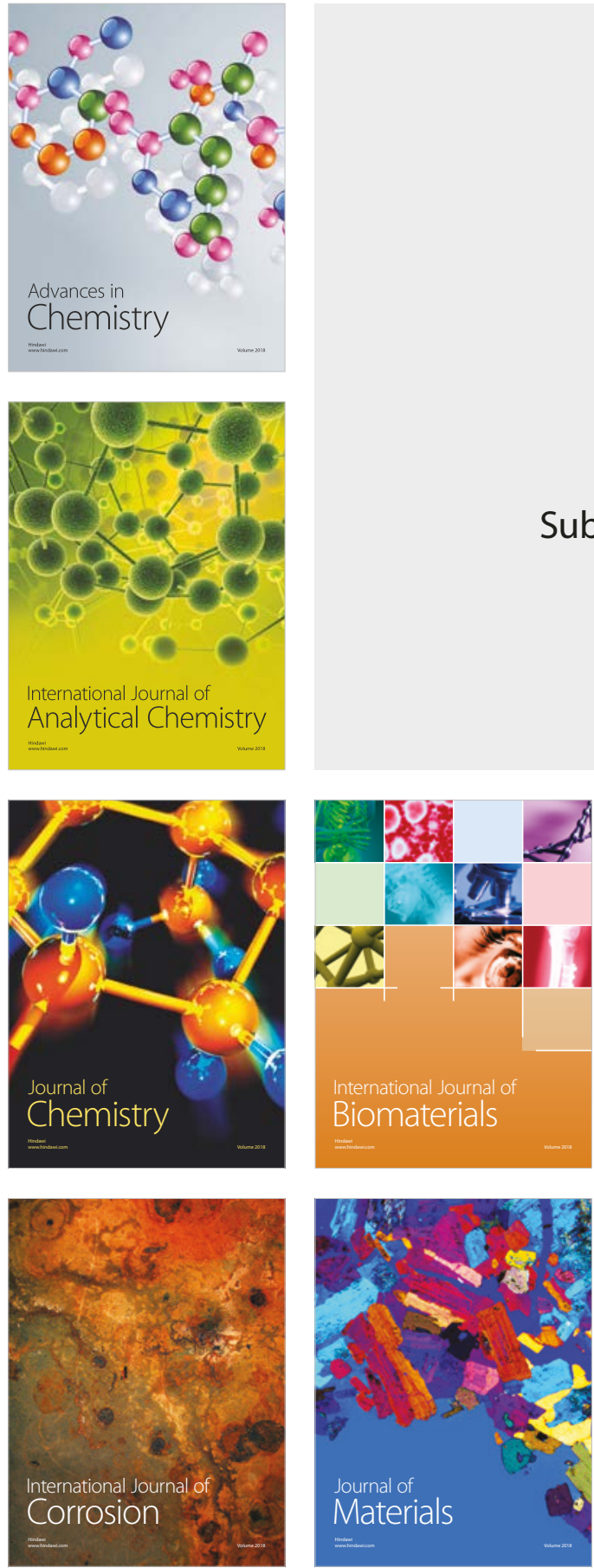

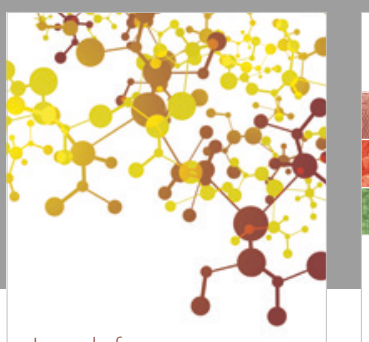

Journal of

Applied Chemistry
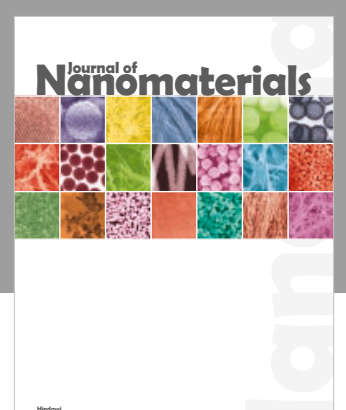

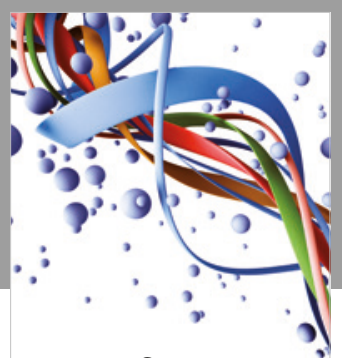

Scientifica

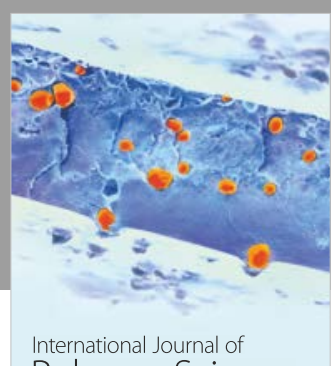

Polymer Science

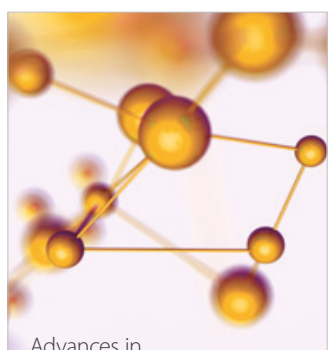

Physical Chemistry
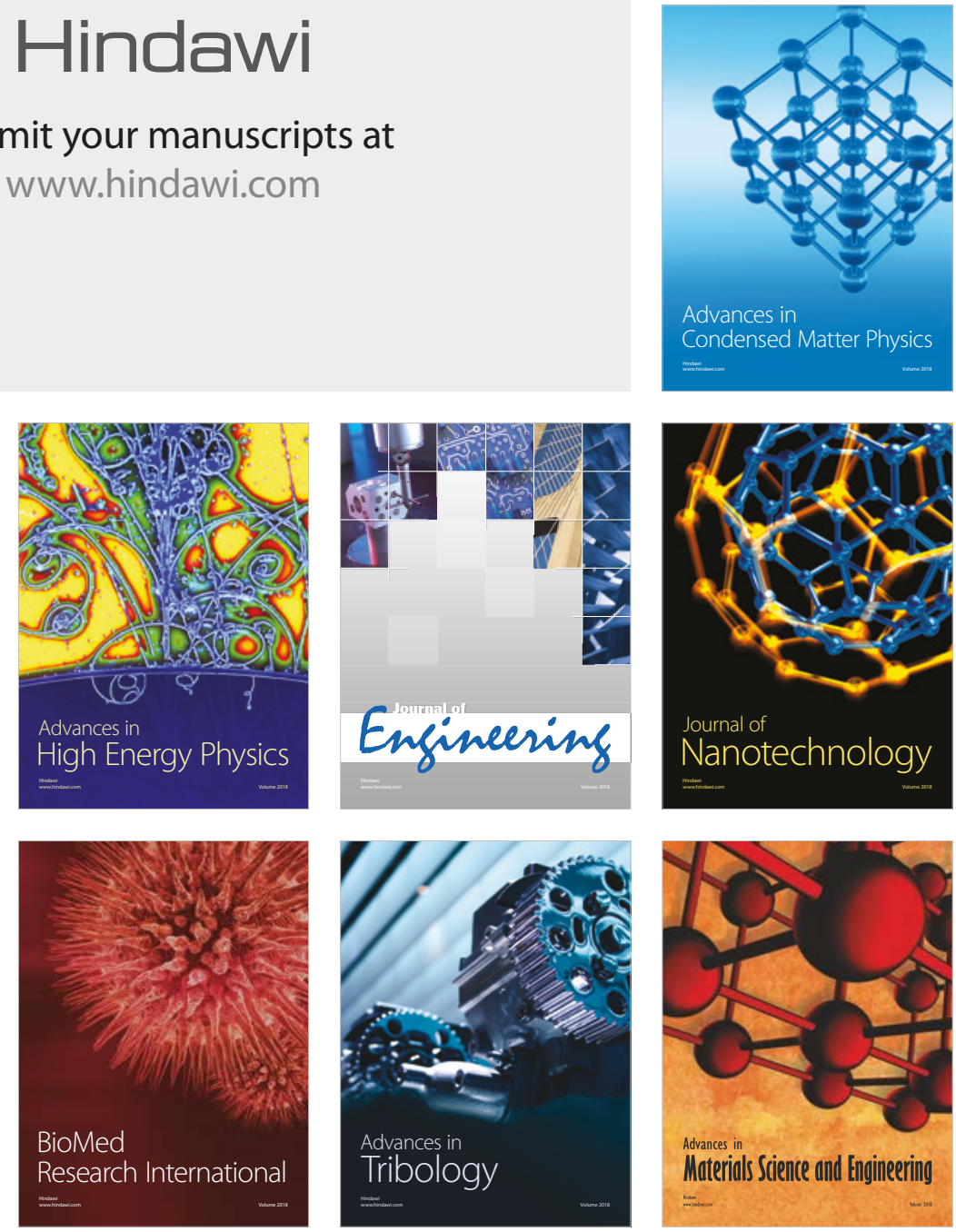